\title{
Neuroinflammatory signals enhance the immunomodulatory and neuroprotective properties of multipotent adult progenitor cells
}

Stylianos Ravanidis ${ }^{1}$, Jeroen F. J. Bogie ${ }^{1}$, Raf Donders ${ }^{1}$, David Craeye ${ }^{2}$, Robert W. Mays ${ }^{3}$, Robert Deans ${ }^{3}$, Kristel Gijbels ${ }^{2}$, Annelies Bronckaers ${ }^{1}$, Piet Stinissen ${ }^{1}$, Jef Pinxteren ${ }^{2}$ and Niels Hellings ${ }^{1 *}$

\begin{abstract}
Introduction: Stem cell-based therapies are currently widely explored as a tool to treat neuroimmune diseases. Multipotent adult progenitor cells (MAPC) have been suggested to have strong immunomodulatory and neuroprotective properties in several experimental models. In this study, we investigate whether MAPC are of therapeutic interest for neuroinflammatory disorders such as multiple sclerosis by evaluating their capacities to modulate crucial pathological features and gain insights into the molecular pathways involved.
\end{abstract}

Methods: Rat MAPC were treated with combinations of pro-inflammatory cytokines that are closely associated with neuroinflammatory conditions, a process called licensing. mRNA expression of immunomodulatory molecules, chemokines and chemokine receptors was investigated. The migratory potential of licensed rat MAPC towards a broad spectrum of chemokines was tested in a Transwell assay. Furthermore, the effect of licensing on the ability of rat MAPC to attract and suppress the proliferation of encephalitogenic T cells was assessed. Finally, neuroprotective properties of rat MAPC were determined in the context of protection from oxidative stress of oligodendrocytes. Therefore, rat MAPC were incubated with conditioned medium of OLN93 cells subjected to sublethal doses of hydrogen peroxide and the gene expression of neurotrophic factors was assessed.

Results: After licensing, a wide variety of immunomodulatory molecules and chemokines, including inducible nitric oxide synthase and fractalkine, were upregulated by rat MAPC. The migratory properties of rat MAPC towards various chemokines were also altered. In addition, rat MAPC were found to inhibit antigen-specific T-cell proliferation and this suppressive effect was further enhanced after pro-inflammatory treatment. This phenomenon was partially mediated through inducible nitric oxide synthase or cyclooxygenase-2. Activated rat MAPC secreted factors that led to attraction of myelin-specific T cells. Finally, exposure of rat MAPC to an in vitro simulated neurodegenerative environment induced the upregulation of mRNA levels of vascular endothelial growth factor and ciliary neurotrophic factor. Factors secreted by rat MAPC in response to this environment partially protected OLN93 cells from hydrogen peroxide-induced cell death.

Conclusions: Rat MAPC possess immune modulatory and neuroprotective properties which are enhanced in response to neuroinflammatory signals. These findings thereby warrant further research to evaluate MAPC transplantation as a therapeutic approach in diseases with an immunological and neurodegenerative component such as multiple sclerosis.

\footnotetext{
* Correspondence: niels.hellings@uhasselt.be

'Hasselt University, Biomedical Research Institute/Transnational University Limburg, School of Life Sciences, Campus Diepenbeek, Agoralaan building C, 3590 Diepenbeek, Belgium

Full list of author information is available at the end of the article
}

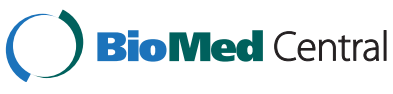

(c) 2015 Ravanidis et al. Open Access This article is distributed under the terms of the Creative Commons Attribution 4.0 International License (http://creativecommons.org/licenses/by/4.0/), which permits unrestricted use, distribution, and reproduction in any medium, provided you give appropriate credit to the original author(s) and the source, provide a link to the Creative Commons license, and indicate if changes were made. The Creative Commons Public Domain Dedication waiver (http://creativecommons.org/publicdomain/zero/1.0/) applies to the data made available in this article, unless otherwise stated. 


\section{Introduction}

Stem cell transplantation represents a promising therapeutic approach to treat neuroinflammatory and neurodegenerative disorders. By using experimental murine models of neuroinflammatoy diseases, such as experimental autoimmune encephalomyelitis (EAE), traumatic brain injury (TBI) and spinal cord injury (SCI), several studies demonstrated that stem cells reduce neurological deterioration and protect the central nervous system (CNS) from further damage and even stimulate its repair [1-7]. In these studies both adult-derived bone marrow mesenchymal stem cells (MSCs) and newborn CNS-derived neural stem cells (NSCs) provided neurotrophic support and even replaced damaged oligodendrocytes and neurons [3-5]. Of note, the therapeutic action of transplanted cells did not relate to the route of administration-peripheral- or CNSdirected. In addition to the neuroprotective and regenerative potential, the immunomodulatory properties of NSCs and MSCs have been well established [1, 2, 8]. NSCs and MSCs were found to suppress the reactivity of encephalitogenic $\mathrm{T}$ cells in the EAE model, thereby likely ameliorating pathological features and clinical symptoms. Collectively, these findings indicate that stem cells can not only halt neuroinflammation but also stimulate CNS repair upon inflammatory neurodegeneration. These properties make them an interesting tool for the treatment of all pathophysiological facets of multiple sclerosis (MS). However, the use of CNS-derived NSCs for autologous transplantation is not a feasible option. Furthermore, although MSCs have been used in clinical trials for autoimmune diseases, the signs of replicative senescence that are demonstrated remain an obstacle for their use as a large-scale clinical product [9-13].

In 2002, another bone marrow-derived stem cell population of mesenchymal origin was initially described, named multipotent adult progenitor cells (MAPC) [14]. Interestingly, in contrast to MSCs, MAPC do not show signs of replicative senescence and possess broader expansion capacities [9-11, 14]. MAPC, in contrast to MSCs, have an extensive differentiation potential towards cell types of all three germ layers depending on the expression levels of pluripotency genes such as oct-4 [14-16]. Importantly, recent studies indicate that MAPC have neuroprotective and immunosuppressive properties. Rat MAPC (rMAPC) were found to preserve hippocampal cell loss in an animal model of hypoxia-ischemia [17], while human MAPC (hMAPC) stimulated recovery in an animal model of TBI, likely through splenocyte-triggered modulation of microglia phenotype [18-20]. Yet other studies revealed that murine MAPC (mMAPC) attenuate alloreactive T-cell proliferation [21] while hMAPC suppress natural killer (NK) cell proliferation in an indoleamine 2,3-dioxygenase 1 (Ido-1)-dependent manner [22]. Therefore, while MAPC possess intrinsic immune modulating and neuroprotective properties, they show superior features over MSCs, such as the broader expansion rate without any obvious genetic abnormalities [9, 14]. These features make MAPC a more attractive candidate for potential stem cell transplantation therapies in CNS disorders, such as MS, TBI and SCI.

In this study, we defined the therapeutic potential of MAPC in neuroinflammatory diseases. For this purpose, we determined the basal immunomodulatory, migratory, chemoattractive and neuroprotective features of rMAPC. Next, the impact of pro-inflammatory and neurodegenerative stimuli on the physiology of rMAPC was assessed. It was previously reported that a pro-inflammatory milieu markedly alters the physiology of stem cells (a process called 'licensing') [23-26]. rMAPC were licensed with combinations of interferon gamma (IFNY), tumor necrosis factor alpha (TNF $\alpha$ ) and interleukin-1 beta (IL1 $\beta)$. These cytokines are highly expressed in the brain parenchyma and cerebrospinal fluid in CNS neuroinflammatory diseases and play a crucial role in their pathophysiology. Particularly, IFNY secreted by Th1 cells leads to the activation of other immune cells whereas TNF $\alpha$ and IL1 $\beta$ secreted by activated macrophages and microglia lead to direct destruction of myelin sheath and oligondendrocytes [27-30]. We show that unstimulated rMAPC possess immunomodulatory and neuroprotective properties which are further enhanced when challenged with neuroinflammatory signals. Specifically, rMAPC suppressed autoreactive Tcell proliferation and protected oligodendrocytes from hydrogen peroxide $\left(\mathrm{H}_{2} \mathrm{O}_{2}\right)$-induced damage. We further present that licensing increases the capacity of rMAPC to attract $\mathrm{T}$ cells, while they themselves adopt an enhanced migratory profile. Collectively these findings show that rMAPC, when challenged in vitro with signals that are overexpressed in a neuroinflammatory environment, acquire a phenotype which may limit disease activity in vivo.

\section{Materials and methods \\ rMAPC culture and inflammatory licensing}

Lewis rMAPC and culture medium were provided by ReGenesys (Leuven, Belgium). rMAPC were isolated and maintained according to a previously described protocol [15]. Briefly, bone marrow from tibiae and femur from Lewis rats was excised and flushed using phosphatebuffered saline (PBS; Lonza, Verviers, Belgium). The single cell suspension was centrifuged and washed using rMAPC medium. rMAPC medium consisted of $60 \%$ Dulbecco's modified Eagle's medium (DMEM; Gibco, Life Technologies Europe B.V., Gent, Belgium) low glucose (1 g/l) , $40 \%$ MCDB-201 medium (pH 7.2), 1× linoleic acid-bovine serum albumin (BSA), $10^{-4} \mathrm{M}$ L-Ascorbic acid, $0.05 \mu \mathrm{M}$ dexamethasone, $55 \mu \mathrm{M}$ 2-mercapto-ethanol (all from Sigma Aldrich, Diegem, Belgium), $100 \mathrm{IU} / \mathrm{ml}$ penicillin and $100 \mu \mathrm{g} / \mathrm{ml}$ streptomycin (Invitrogen, Life Technologies 
Europe B.V.), $1 \times$ insulin-transferrin-selenium (Lonza), 10 $\mathrm{ng} / \mathrm{ml}$ mouse epidermal growth factor, $10 \mathrm{ng} / \mathrm{ml}$ recombinant human platelet-derived growth factor ( R \& D systems, Abingdon, United Kingdom), $2 \%$ fetal bovine serum (Hyclone, EU approved, Cat CH30160.03), and $10^{3}$ units/ $\mathrm{ml}$ mouse leukemia inhibitory factor (Millipore). Cells were seeded in fibronectin (10 ng/ml; Sigma Aldrich) coated plates for 1 month in increasing densities. After 1 month of culturing, negative control selection was performed to eliminate $\mathrm{CD} 45^{+}$hematopoietic cells. The resulted cell fraction was subcloned until a homogeneous population of small, spindle-shaped cells remained. The cells with MAPC morphology were maintained in culture in order for colonies to be formed. Frozen stock was created with cells in medium containing rMAPC medium, fetal bovine serum and dimethyl sulfoxide (DMSO). Cells were maintained in T175 flasks (Cellstar, Greiner Bio-One, Vilvoorde, Belgium) or petri dishes (Nunc, VWR, Leuven, Belgium) according to the purposes needed and maintained at $37{ }^{\circ} \mathrm{C} / 5 \% \mathrm{O}_{2}$. All experiments were performed with rMAPC that reached 10 population doublings maximum.

To assess the impact of pro-inflammatory treatment (licensing) on rMAPC properties, cells were treated with $100 \mathrm{ng} / \mathrm{ml}$ of combinations of rat recombinant cytokines $(\mathrm{IFN} \gamma+\mathrm{TNF} \alpha, \mathrm{IFN} \gamma+\mathrm{IL} 1 \beta, \mathrm{TNF} \alpha+\mathrm{IL} 1 \beta$; all from Peprotech, London, UK) or PBS as vehicle control for 12 or 24 hours. Specific licensing incubation times are described in each section.

\section{Colony forming unit fibroblast assay}

Cells were seeded as 10 cells $/ \mathrm{cm}^{2}$ in six-well plates. Medium was changed every 2 days. After 12 days, medium was removed and cells were fixed with $4 \%$ paraformaldehyde (PFA) for 20 minutes and then were washed twice with PBS. A solution of $0.5 \%$ crystal violet (Sigma Aldrich) in methanol was added for $30 \mathrm{mi}$ nutes. Following the incubation time, cells were washed three times with PBS, rinsed with tap water and allowed to air dry before measuring the colonies. To explore the impact of licensing on the ability of rMAPC to form colonies, cells were pre-treated for 24 hours with the three combinations of cytokines and vehicle.

\section{Flow cytometry}

Cells were detached with $0.25 \%$ trypsin (Gibco), harvested and washed with fluorescence-activated cell sorting (FACS) buffer (PBS supplemented with $2 \%$ fetal calf serum (FCS; Gibco)) and incubated in the dark for 30 minutes at $4{ }^{\circ} \mathrm{C}$ with surface antibodies. Phenotypic analysis of the cells was performed using CD11b/c, CD31 (BD Biosciences, Erembodegem, Belgium), CD44 (Immunotools, Friesoythe, Germany), CD80, CD86 (eBioscience, Vienna, Austria), RT-1a and RT-1b (Biolegend, San Diego,
CA, USA). Cells were positive for CD44 and RT-1a, expressed low to negligible levels of $\mathrm{CD} 80$, while they were completely negative for CD11b/c, CD31, CD86 and RT-1b.

\section{Generation of myelin basic protein-specific T cells}

Myelin basic protein (MBP)-specific T cells were isolated as described previously [31]. Briefly, 8-week-old female Lewis rats (Janvier, France) were injected subcutaneously with a $0.1 \mathrm{ml}$ solution of $250 \mu \mathrm{g} / \mathrm{ml}$ guinea pig MBP, 2.5 $\mathrm{mg} / \mathrm{ml} \mathrm{H37RA} \mathrm{heat-killed} \mathrm{mycobacterium} \mathrm{tuberculosis}$ (Difco, Detroit, USA) and $60 \mu$ l Complete Freund's adjuvant (Sigma Aldrich) in both hind paws. Ten days postimmunization, popliteal and inguinal lymph nodes were removed and single cell suspensions were obtained by grinding the tissues through a $70 \mu \mathrm{m}$ cell strainer with a syringe plunger. The isolated cells were seeded initially in T cell medium consisting of RPMI-1640 medium, $1 \%$ penicillin-streptomycin mixture, $1 \%$ non-essential amino acids, $1 \%$ sodium pyruvate (all from Invitrogen, Life Technologies Europe B.V.), $20 \mu \mathrm{M}$ 2-mercapto-ethanol (Sigma Aldrich) supplemented with $2 \%$ heat-inactivated autologous serum and $33 \mu \mathrm{g} / \mathrm{ml}$ MBP. After 48 hours, T cells were collected, washed and seeded in T cell medium supplemented with $10 \%$ FCS (Gibco) and $6.5 \%$ CAS medium (supernatant of Concanavalin A (Sigma Aldrich) activated spleen cells) for another 48 hours. Next, cells were collected, washed and seeded in T cell medium supplemented with $10 \%$ FCS for 3 days. All animal experiments were approved by the Ethical Committee for Animal Experiments of Hasselt University.

\section{Co-cultures}

Prior to co-culture with rMAPC, T cells were labeled with $4 \quad \mu \mathrm{M}$ carboxyfluorescein diacetatesuccinimidyl ester (CFSE; Invitrogen) at a concentration of $2 \times 10^{7}$ cells $/ \mathrm{ml}$ in PBS/0.1 \% BSA (Millipore, Merck Chemicals N.V./S.A., Overijse, Belgium) solution. CFSE-labeled T cells $\left(7.5 \times 10^{4}\right.$ cells/ well $)$ were seeded alongside rMAPC in ratios ranging from 1:0.5 to 1:2 (T cells/rMAPC). Irradiated thymocytes $\left(7.5 \times 10^{4}\right.$ cells/well, $\left.3000 \mathrm{rad}\right)$ were added to each well as antigen-presenting cells. The medium of the co-cultures consisted of a 1:1 mixture of rMAPC medium and T cell medium with $2 \%$ autologous serum supplemented with $10 \mu \mathrm{g} / \mathrm{ml} \mathrm{MBP.} \mathrm{To}$ explore the effect of licensing on their suppressive capacity, rMAPC were pre-treated with the three combinations of cytokines and vehicle for 12 hours prior to the co-culture. To define the involvement of nitric oxide (NO), cyclooxygenase (COX)-2 and Ido-1 in suppressive activity, respectively $1.5 \mathrm{mM} \mathrm{L}-\mathrm{N}^{\mathrm{G}}$-monomethyl arginine citrate (L-NMMA;VWR), $10 \mu \mathrm{M}$ indomethacin (Sigma Aldrich) and $200 \mu \mathrm{M}$ 1-methyl-L-tryptophan/ 1-methyl-D-tryptophan (1-Mt-L and 1-Mt-D; Sigma 
Aldrich) were added at day 0 and day 2 of the co-culture. After 4 days, flow cytometry was used to assess proliferation and cell death of lymphocytes. Therefore, cells were stained with phycoerythrin-conjugated mouse anti-rat CD3 (eBioscience) and 7 aminoactinomycin D (7AAD; BD Biosciences). T-cell proliferation was determined based on CFSE dye dilution of $\mathrm{CD}^{+} 7 \mathrm{AAD}^{-}$cells using flow cytometry (FACSCalibur).

\section{Migration assays}

To explore the chemoattractive properties of rMAPC, we seeded MBP-specific T cells $\left(2.5 \times 10^{5}\right.$ cells/insert $)$ in the upper chamber of a transwell plate with a $5-\mu \mathrm{m}$ pore size (Sigma Aldrich). In the bottom chamber supernatant of (licensed) rMAPC was placed. To obtain the supernatants, rMAPC were seeded in a mixture of media (30 \% MAPC medium, 70 \% RPMI-1640) and licensed for 24 hours with respective cytokine combinations. The supernatant was aspirated and filtered through a $0.45-\mu \mathrm{m}$ filter. Following 4 hours of culture at $37^{\circ} \mathrm{C}$, migrated cells were collected from the bottom chamber and counted using a hemocytometer. Non-conditioned medium served as negative control.

To explore the functionality of chemokine receptors expressed by rMAPC, rat recombinant CCL2, CCL5, $\mathrm{CX}_{3} \mathrm{CL} 1, \mathrm{CXCL10}$ and CXCL12 $\alpha$ (100, 250 and $500 \mathrm{ng} / \mathrm{ml}$, all from Peprotech) were administered in the bottom chamber of a transwell plate with an $8-\mu \mathrm{M}$ pore size (Sigma Aldrich). Cells were seeded in the upper chamber at a concentration of $5 \times 10^{4}$ cells/insert and allowed to migrate for 16 hours. Recombinant chemokines were diluted in DMEM-low glucose $1 \mathrm{~g} / \mathrm{l}$ (Gibco). DMEM (glucose $1 \mathrm{~g} / \mathrm{l}$ ) was used as negative control. As a positive control, rMAPC medium (ReGenesys) was used, as it was optimized to be more effective than the more traditionally used FCS containing solutions (20 \% FCS in DMEM $1 \mathrm{~g} / \mathrm{l}$ solution (see Additional file 1)). To explore the impact of inflammatory conditions on the migration profile of rMAPC, cells were licensed for 12 hours before allowing them to migrate. For the quantification of the migrated fraction we used a protocol by Bronckaers et al. [32] with minor modifications. Briefly, cells on both sides of the insert were fixed with $4 \%$ PFA solution for 20 minutes. Following one washing step with PBS, cells were incubated with $0.1 \%$ crystal violet (Sigma Aldrich) solution in ethanol for 10 minutes at room temperature. Next, cells on the top side of the insert were removed with a cotton swab and an additional washing step with PBS was performed. Wells were allowed to air dry; thereafter, two pictures from each well were taken. Finally, the migrated fraction was analyzed using ImageJ software and expressed as percentage of the total covered area [33].

\section{OLN93 cell culture, generation of conditioned media and protection assays}

The OLN93 cell line was a kind gift from Prof. Dr. C. Richter-Landsberg (University of Oldenburg). Cells were cultured in DMEM high glucose (Sigma Aldrich) supplemented with $10 \%$ FCS and $1 \%$ penicillin-streptomycin mixture at $37{ }^{\circ} \mathrm{C} / 10 \% \mathrm{CO}_{2}$. Conditioned media from rMAPC were prepared according to the protocol of Isele et al. [34] with minor modifications. An illustration of the protocol is depicted in Additional file 2. Briefly, OLN93 were seeded in a 96-well flat bottom plate (Greiner Bio-One) $\left(5 \times 10^{4}\right.$ cells/well $)$ and then treated with $1 \mathrm{mM}$ $\mathrm{H}_{2} \mathrm{O}_{2}$ to induce sublethal cell damage. After 2 hours, $\mathrm{H}_{2} \mathrm{O}_{2}$ was removed and OLN93 were allowed to condition fresh medium for 24 hours $\left(\mathrm{OLN}-\mathrm{CM}_{\mathrm{H} 2 \mathrm{O} 2}\right)$. Non-damaged OLN93 cells provided the OLN-CM. The OLN-CM $\mathrm{H}_{2} \mathrm{O} 2$ and OLN-CM were applied to rMAPC in a 96-well flat bottom plate $\left(5 \times 10^{4}\right.$ cells/well) for 18 hours resulting in double-conditioned media (DCM). These media are designated as $\mathrm{DCM}_{\mathrm{H} 2 \mathrm{O} 2}$ and $\mathrm{DCM}_{\text {null }}$, respectively. rMAPC treated with $\mathrm{OLN}-\mathrm{CM}_{\mathrm{H} 2 \mathrm{O} 2}$ and $\mathrm{OLN}-\mathrm{CM}$ were also processed for RNA extraction $\left(5 \times 10^{5}\right.$ cells/well per 24-well plate) to evaluate alterations in gene expression levels of neurotrophic factors. All the aforementioned conditioned media were collected and filtered through a $0.45-\mu \mathrm{m}$ filter.

OLN-93 cells were allowed to adhere in a 96-well flat bottom plate $\left(5 \times 10^{4}\right.$ cells/well $)$ and exposed to $\mathrm{DCM}_{\mathrm{H} 2 \mathrm{O} 2}$ and $\mathrm{DCM}_{\text {null }}$ for 6 hours (see Additional file 2). Subsequently, cells were subjected to $\mathrm{H}_{2} \mathrm{O}_{2}$-induced oxidative stress $\left(1 \mathrm{mM}, 1.5 \mathrm{mM}\right.$ and $2 \mathrm{mM} \mathrm{H}_{2} \mathrm{O}_{2}$ for 24 hours). OLN93 cell viability was determined using the MTT assay.

\section{Gene expression analysis}

rMAPC licensed for 12 hours and rMAPC treated with OLN93-derived media (OLN-CM $\mathrm{H}_{2} \mathrm{O} 2$ and OLN-CM) for 18 hours were processed for gene expression analysis. Cells were detached, centrifuged and stored in lysis buffer of RNeasy mini kit (QIAGEN, Venlo, The Netherlands) at $-80{ }^{\circ} \mathrm{C}$ until later use.

RNA was isolated with the RNeasy mini kit (QIAGEN) and was reversely transcribed into complementary DNA (cDNA) using the Quanta kit (VWR, Leuven, Belgium) following the manufacturer's instructions. cDNA was subsequently used for semi quantitative real-time polymerase chain reaction (RT-PCR). Quantitative PCR reactions were performed with a StepOnePlus ${ }^{\mathrm{ma}}$ Real-Time PCR System (Applied Biosystems) in micro-AMP Fast Optical 96-well reaction plates in a total volume of $10 \mu \mathrm{l}$ per reaction. The reaction mix contained $1 \times$ Fast SYBR green master mix (Applied Biosystems), $10 \mathrm{mM}$ of each primer (designed with Primer 3 [35]; Eurogentec, Liege, Belgium), nuclease-free water and $12.5 \mathrm{ng}$ of cDNA template. The amplification protocol used was the following: 
20 seconds at $95{ }^{\circ} \mathrm{C}$, followed by 40 cycles of 3 seconds at $95{ }^{\circ} \mathrm{C}$ and 30 seconds at $60{ }^{\circ} \mathrm{C}$, and subsequent melting-curve analysis. All the primer sequences used are listed in Additional file 3. Relative quantification of gene expression was calculated using the $2^{-\Delta \Delta C t}$ method [36] and data were normalized to the most stable reference genes for each experiment according to geNorm [37]. For visualization of mRNA transcript presence, PCR amplified products (Hoffmann-La Roche, Basel, Switzerland) were separated in a $1.5 \%$ agarose gel and were visualized with ethidium bromide.

\section{Nitrite formation and cytokine release}

Supernatants of licensed rMAPC (24 hours) and cocultures were collected and release of $\mathrm{NO}$ was determined using the Griess reagent system (Promega, Leuven, Belgium) following the manufacturer's instructions. Absorbance was measured at $550 \mathrm{~nm}$ using a microplate reader (Bio-Rad Benchmark, Bio-Rad Laboratories, Hercules, CA, USA).

IFN $\gamma$ release was measured in the co-culture supernatant using Rat IFN $\gamma$ enzyme-linked immunosorbent assay (Peprotech) following the manufacturer's instructions. Absorbance was measured at $415 \mathrm{~nm}$.

\section{Cell viability assay (MTT)}

Cell survival and proliferation was assessed with MTT assay (Sigma Aldrich). Briefly, $12.5 \mu \mathrm{l} \mathrm{MTT} \mathrm{(3-(4,5)-di-}$ methylthiazol-(-z-y1)-3,5-diphenytetrazoliumronide) dissolved in $100 \mu \mathrm{l}$ medium per well was added for 4 hours at $37^{\circ} \mathrm{C}$. After incubation, MTT was removed and a mixture of $25 \mu \mathrm{l}$ glycine and $150 \mu \mathrm{l}$ DMSO/well was added and the absorbance was determined at $540 \mathrm{~nm}$.

\section{Statistical analysis}

Data were analyzed with the GraphPad Prism version 5.00 for Windows, (GraphPad Software, San Diego California USA [38]) and are presented as mean \pm SEM. D'Agostino and Pearson omnibus normality test was used to test normal distribution. Parametrical data were analyzed using unpaired student $t$ test or one way analysis of variance followed by Dunnett multiple comparisons test. Data that did not follow normal distribution were analyzed using Mann Whitney and Kruskal-Wallis followed by Dunns multiple comparison test. Differences with $P$ value $\leq 0.05$ were considered significant.

\section{Results}

In vitro licensing does not affect the viability and colony forming ability of rMAPC

When stem cells are to be used in treating inflammatory diseases, they will be challenged by a high proinflammatory environment. To evaluate whether inflammatory conditions lead to alterations of basic biological functions, we assessed cell viability and colony formation ability following in vitro treatment with combinations of IFN $\gamma, T N F \alpha$ and IL1 $\beta$. We show that the viability of rMAPC was not affected after 24 hours treatment (Fig. 1a). Similar, the ability of rMAPC to form colonies was not hampered following pre-treatment with proinflammatory cytokines (Fig. 1b). These findings indicate that an inflammatory environment does not affect basic biological functions of rMAPC.

\section{In vitro licensing leads to upregulation of immunomodulatory genes}

The immune suppressive and neuroprotective features of MSCs are enhanced in the context of neuroinflammatory conditions [23]. We investigated whether the expression of immunomodulatory molecules of rMAPC is changed upon in vitro challenge with selected proinflammatory cytokines. Inducible nitric oxide synthase (iNOS), Ido-1, COX2, programmed death-ligand 1 (PDL1) and TNF-stimulated gene 6 protein (TSG-6) have been proposed as possible mechanisms of immune suppression among others [39-43]. iNOS mRNA levels were significantly upregulated in rMAPC following IFN $\gamma+$ TNF $\alpha$ and TNF $\alpha+$ IL1 $\beta$ treatment (Fig. 2a). In line with this, NO levels increased in the culture medium (Fig. 2b). TNF $\alpha+$ IL1 $\beta$ induced the upregulation of TSG-6 and $C O X-2$ mRNA levels. IFN $\gamma$ was the main inducer of $P D$ $L 1$ as TNF $\alpha+$ IL1 $\beta$ did not show any effect (Fig. 2a). Ido- 1 was only detected after IFN $\gamma+\mathrm{TNF} \alpha$ treatment (Fig. 2c). COX-1 was decreased following TNF $\alpha+$ IL1 $\beta$ treatment while heme oxygenase 1 (HO- 1 ) expression was not altered under any of the treatments (see Additional file 4).

Hepatocyte growth factor (HGF) has been suggested to be responsible for neuroprotective and immunomodulatory features of murine MSCs in EAE [44]. In our study, we detected negligible levels of $H G F$ in rMAPC in all conditions tested.

The upregulation of inflammatory cytokines by stem cells could potentially counteract their immune suppressive role and enhance inflammation [27-29]. We found a minimal but significant upregulation of $I F N \gamma$ and TNF $\alpha$ after IFN $\gamma+$ IL1 $\beta$ and TNF $\alpha+\operatorname{IL} 1 \beta$ treatment, respectively. $I L-6$ expression was not affected under any of the cytokine combinations (see Additional file 4).

Together, these results suggest that rMAPC, when encountering a pro-inflammatory environment, are triggered to secrete a variety of immunomodulatory molecules.

\section{rMAPC suppress proliferation of encephalitogenic T cells}

To elucidate whether rMAPC are suppressive towards T cells, we performed co-culture experiments with MBPspecific $\mathrm{T}$ cells as a model of encephalitogenic $\mathrm{T}$ cells. MBP-reactive $\mathrm{T}$ cells are evident in diverse neurological 

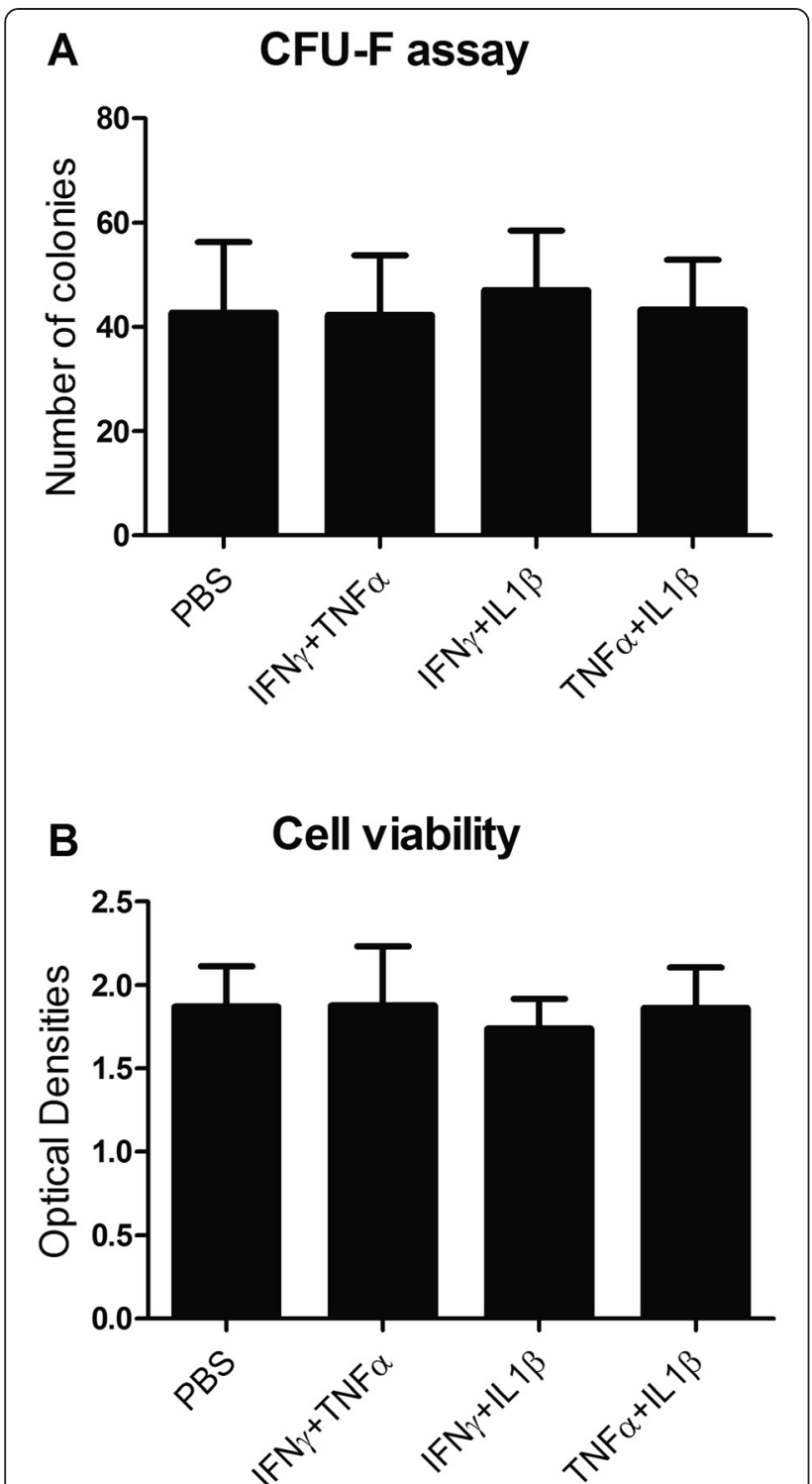

Fig. 1 Inflammatory cytokine treatment is not toxic and does not affect colony formation of rMAPC. a rMAPC were tested for the formation of colonies following exposure to combinations of inflammatory cytokines ( $\mathrm{n}=3$ experiments, duplicates per experiment). The total number of colonies is shown. $\mathbf{b}$ Cell viability was measured after 24-hour treatment with combinations of pro-inflammatory cytokines. Optical density values are depicted ( $n=4$ experiments, triplicates per experiment). CFU-F colony-forming unit-fibroblasts, IFN interferon, IL interleukin, PBS phosphate-buffered saline, TNF tumor necrosis factor

disorders such as MS, TBI, SCI and stroke [45-47]. We demonstrate that rMAPC potently suppressed T-cell proliferation in response to MBP even at the lowest ratio (1:0.5). Increasing the number of rMAPC did not further enhance the inhibition of T-cell proliferation (Fig. 3a). The observed effect was not due to cell death, as the percentage of $\mathrm{CD}^{+} 7 \mathrm{AAD}^{+}$cells was not altered (data not shown). In addition, a decrease in IFN $\gamma$ was detected when increasing amounts of rMAPC were added (Fig. 3b). Of note, NO also decreased in a similar way, in line with the observation that IFN $\gamma$ induces release of NO by MAPC (Fig. 2a, b). Activated T cells or thymocytes alone did not produce NO (Fig. 3c).

\section{Inflammatory treatment enhances the suppression of myelin-specific T-cell proliferation}

Next, we investigated whether the pro-inflammatory cytokine treatment enhances the suppressive properties of rMAPC towards MBP-specific T cells in line with previous findings for MSCs [40, 43]. Inhibition of antigenspecific T-cell proliferation was enhanced when cells were pre-licensed with either IFN $\gamma+\mathrm{TNF} \alpha$ or TNF $\alpha+$ IL1 $\beta$. Of note, pre-licensed rMAPC completely inhibited the antigen-specific $\mathrm{T}$-cell proliferation reaching the negative control levels. For IFNY + IL1 $\beta$, no increased suppression was found (Fig. 4a).

To identify the mechanisms involved, we applied selective inhibitors for immune modulatory molecules, taking into consideration the upregulation of immunomodulatory genes reported in this study (Fig. 2a). Specifically, we used inhibitors for iNOS (L-NMMA), COX-2 (indomethacin) and Ido-1 (two isoforms; 1-Mt-L, 1-MtD). Blockade of $\mathrm{NO}$ reversed the observed enhancement of T-cell suppression to the levels observed when MAPC were not pre-treated with pro-inflammatory cytokines (Fig. 4b, c). Furthermore, COX-2 inhibition abrogated the enhanced suppression observed when MAPC were pre-treated with TNF $\alpha+$ IL1 $\beta$ (Fig. 4c). Ido-1 inhibitors did not have any reversible effect (Fig. 4b). The inhibitors alone did not have any effect on T-cell proliferation following exposure to MBP (see Additional file 5). Together, these results demonstrate that rMAPC are able to suppress the proliferation of encephalitogenic $\mathrm{T}$ cells when restimulated with cognate antigen.

\section{rMAPC acquire a chemoattractive profile following licensing}

$\mathrm{T}$ cell chemotaxis is crucial for the suppression of T-cell proliferation by MSCs [43]. rMAPC constitutively express mRNA copies of certain chemokines that are massively increased after inflammatory treatment. IFN $\gamma+\mathrm{TNF} \alpha$ led to a significant induction of four out of five chemokines tested. TNF $\alpha+\operatorname{IL} 1 \beta$ upregulated three out of five of the chemokines, while IFN $\gamma+$ IL1 $\beta$ only significantly induced CXCL10 (Fig. 5a, Additional file 4).

To confirm the secretion of chemokines in the culture medium following inflammatory treatment, we allowed MBP-specific T cells to migrate towards supernatants of conditioned medium from licensed rMAPC. Enhanced T-cell migration was observed towards supernatant of rMAPC after treatment with TNF $\alpha+$ IL1 $\beta$ and to a lesser extent after IFN $\gamma+$ TNF $\alpha$ pre-treatment. No 


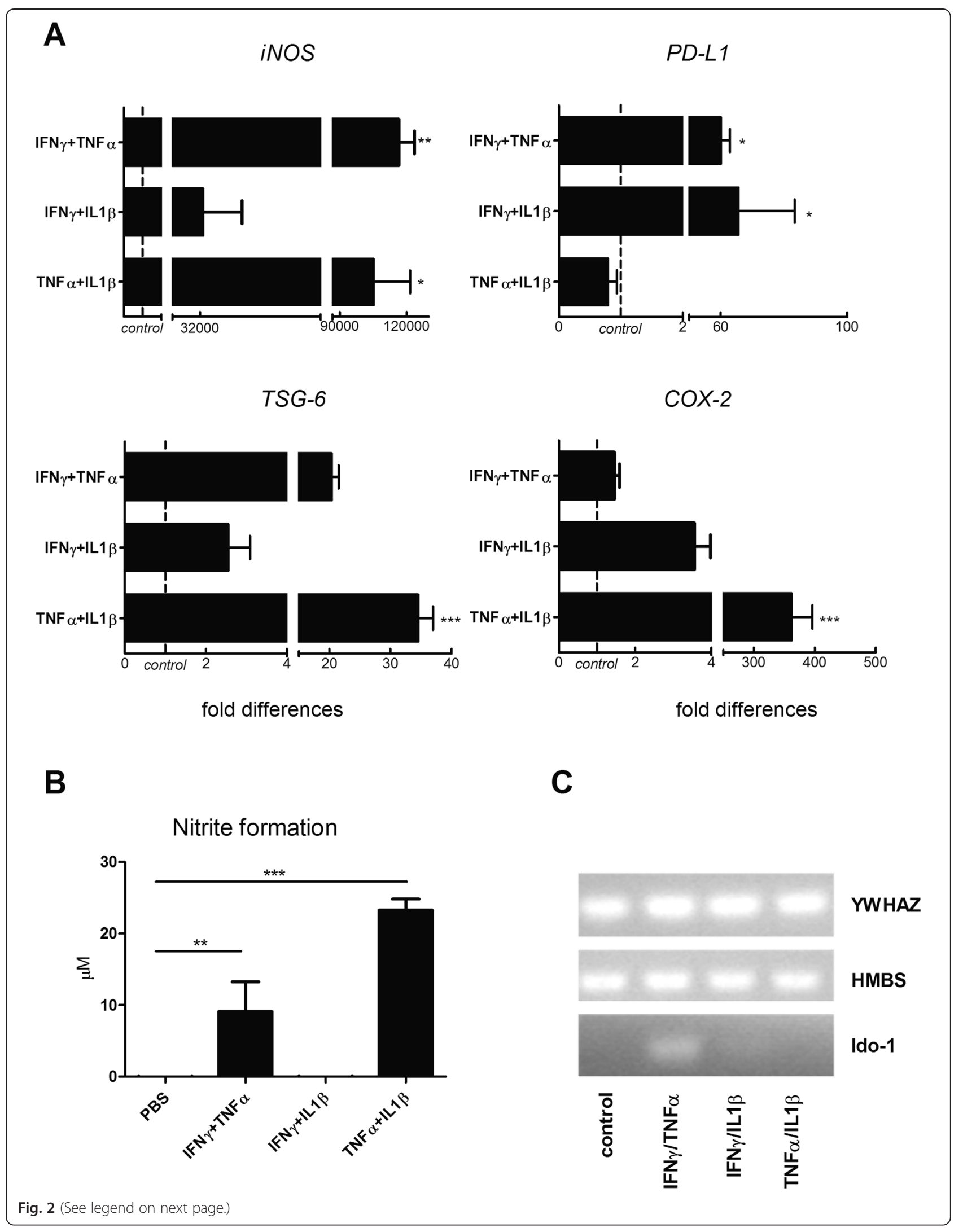


(See figure on previous page.)

Fig. 2 Pro-inflammatory cytokines induce the upregulation of immune modulatory genes by rMAPC. a Gene expression of immunomodulatory molecules by rMAPC following treatment with respective inflammatory cytokines. Fold differences compared to control (PBS treated, dotted line) are shown. Values represent mean \pm SEM from five independent experiments. $\mathbf{b}$ Measurement of nitrite in the culture supernatant of rMAPC. Concentration of nitrite is shown $(\mu M)$. Mean values $( \pm S E M)$ from four independent experiments. $\mathbf{c}$ Expression of Ido-1 following 12 hours treatment with respective cytokines. YWHAZ and HMBS were used as loading controls. Representative experiment out of $\mathrm{n}=5$ performed. Non-parametrical Kruskal Wallis multiple group comparison test was used followed by Dunns test for differences between groups. Significant differences with the control condition are indicated with asterisks: ${ }^{*} P \leq 0.05,{ }^{* *} P \leq 0.01,{ }^{* * *} P \leq 0.001$. COX cyclooxygenase, HMBS hydroxymethylbilane synthase, IFN interferon, ido-1 indoleamine 2,3-dioxygenase 1, IL interleukin, iNOS inducible nitric oxide synthase, PBS phosphate-buffered saline, PD-L1 programmed death-ligand 1, TNF tumor necrosis factor, TSG TNF stimulated gene, YWHAZ 14-3-3 protein zeta/delta

significant T-cell migration towards supernatant of IFN $\gamma$ + IL1 $\beta$ treated rMAPC was observed (Fig. 5b). These results match with the massive upregulation of chemokine mRNA expression (Fig. 5a). Chemokine receptors were all detected on myelin-specific $\mathrm{T}$ cells used in the migration assay (Fig. 5c).

We conclude that rMAPC are able to exert chemoattraction towards $\mathrm{T}$ cells when challenged with proinflammatory stimuli.

\section{rMAPC express a set of functional chemokine receptors} Chemokine receptors are potentially involved in MSC homing when injected in pathological conditions [48]. Therefore, we sought to explore the chemokine receptor repertoire of rMAPC. We demonstrate that rMAPC express mRNA levels of CCR1, CCR2, CCR9, CXCR3, CXCR4, CXCR5, CXCR6, CXCR7 and $C X_{3}$ CR1. rMAPC did not express detectable levels of CCR3, CCR5, CCR6, CCR7 and CXCR2 (Fig. 6a).

To confirm the functionality of the receptors expressed, we explored the migration of rMAPC towards chemokines known to be expressed during neuroinflammation [49]. rMAPC were able to migrate to all chemokines tested, namely CCL2, CCL5, CX3CL1, CXCL12 $\alpha$ and CXCL10 (Fig. 6b). Generally we observed a dose-dependent increase in chemotaxis in all chemokines used. These results indicate that rMAPC are attracted to neuroinflammatory chemokines.

\section{Licensing affects the expression of chemokine receptors genes and the migration of rMAPC}

Systemic inflammation in the periphery could potentially affect rMAPC migratory behavior and thus dictate migration towards ongoing inflammation in the CNS and lymphoid organs. Following licensing we saw a differential upregulation of chemokine receptors (Fig. 6c, Additional file 4). Specifically, while IFN $\gamma+$ TNF $\alpha$ treatment increased only the expression of CXCR3, IFN $\gamma+\operatorname{IL} 1 \beta$ treatment upregulated CCR9, CXCR3, CXCR5 and $C X_{3} C R 1$. Finally $\mathrm{TNF} \alpha+\mathrm{IL} 1 \beta$ treatment induced the upregulation of $C X C R 7$ and $C X_{3} C R 1$ while it was the only condition where CCR3 expression was induced (data not shown). Of interest, IFN $\gamma+$ TNFa significantly downregulated the expression of CCR1.
We further assessed the migration of rMAPC following inflammatory treatment. We observed selective alterations in the migration pattern of rMAPC upon licensing. In particular, TNF $\alpha+$ IL1 $\beta$ treatment induced an enhanced migration of rMAPC towards CCL5, CXCL12 $\alpha$ and $\mathrm{CX}_{3} \mathrm{CL} 1$, while IFN $\gamma+\mathrm{IL} 1 \beta$ enhanced migration towards CXCL10 (Fig. 6d). The observed results correlate partially with the alterations in the expression of CCR1, CXCR7, $C X_{3} C R 1$ and CXCR3 following inflammatory treatment. Of note, IFN $\gamma+$ TNF $\alpha$ treated rMAPC migrated in a lesser extent towards CCL5, correlating with the significant downregulation in the expression of CCR1. The three combinations did not confer significant alterations on rMAPC migration towards the various concentrations of chemokines, besides the ones illustrated in Fig. 6d. These results indicate that the inflammatory milieu may modify the migratory ability of rMAPC thereby affecting the expression of certain chemokine receptors and subsequent migratory activity.

\section{rMAPC enhance their neuroprotective activity features} when challenged with a neurodegenerative environment

Neurodegeneration-induced secretion of growth factors by bone marrow-derived stem cells leads to protection of oligodendrocytes and neurons [34, 44]. To assess potential neuroprotective features of rMAPC in response to neurodegeneration, we challenged rMAPC with secreted factors from the sublethally damaged $\left(\mathrm{H}_{2} \mathrm{O}_{2}\right)$ oligodendroglia cell line, OLN93 [50]. $\mathrm{H}_{2} \mathrm{O}_{2}$ generates free radicals leading to apoptotic death after oxidative stress, a situation which is prominent within the CNS during neurodegenerative events [51]. We demonstrated that secreted factors released by rMAPC in response to $\mathrm{H}_{2} \mathrm{O}_{2}$-treated OLN93 cells $\left(\mathrm{DCM}_{\mathrm{H} 2 \mathrm{O} 2}\right)$ are able to partially protect OLN93 cells in all three concentrations of $\mathrm{H}_{2} \mathrm{O}_{2}$ used. rMAPC-derived soluble factors in response to non-damaged OLN93 cells ( $\left.\mathrm{DCM}_{\text {null }}\right)$ showed no evidence of protecting OLN93 cells from $\mathrm{H}_{2} \mathrm{O}_{2}$ damage (Fig. 7a). rMAPC viability under the influence of OLN$\mathrm{CM}_{\mathrm{H} 2 \mathrm{O} 2}$ was not affected due to possible toxic factors secreted by early apoptotic cells or $\mathrm{H}_{2} \mathrm{O}_{2}$ remnants (data not shown). OLN93 cells did not show any differences in cell proliferation when allowed to proliferate for 24 hours in normal culture medium after the pre-treatment 


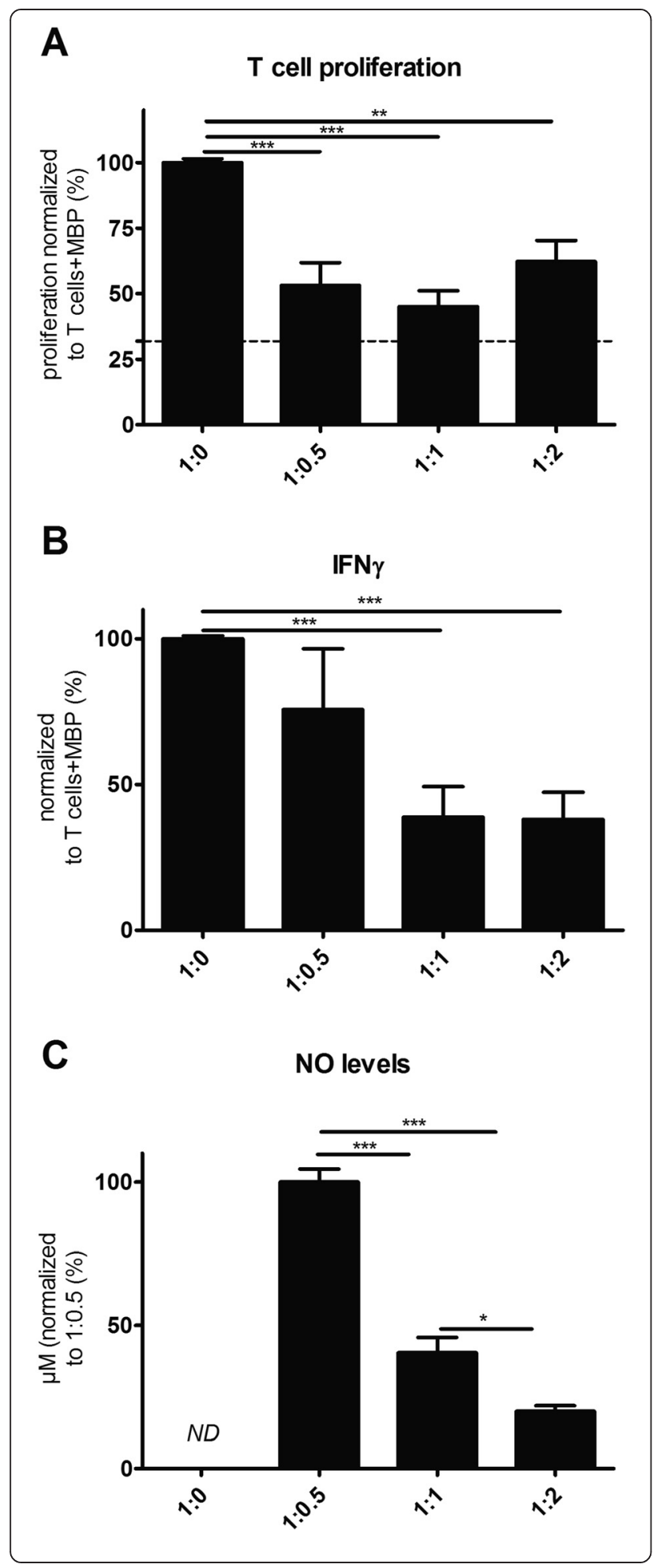

Fig. 3 rMAPC suppress antigen-specific T-cell proliferation and IFNY production. a Co-culture of MBP-specific T cells with rMAPC in increasing ratios (1:0.5 to 1:2). Results are shown as percentage of proliferation normalized to the positive control (1:0, T cells + MBP). Mean values \pm SEM are from three independent experiments, with triplicates per experiment. Negative control (T cells without MBP) is shown as a dotted line. $\mathbf{b}$ IFNy levels measured in the co-culture supernatants with enzyme-linked immunosorbent assay. Results are presented as percentages normalized to the positive control (1:0, T cells $+\mathrm{MBP})$. Mean values \pm SEM are from three experiments, with triplicates per experiment. c Analyses of NO levels in co-culture supernatants through the measurement of nitrite. Results are shown as percentages normalized to the lowest ratio in the co-culture (1:0.5). Mean values \pm SEM are from three independent experiments, with triplicates per experiment. Nitrite was not detected (ND) in the positive control (1:0, T cells + MBP), or in thymocytes alone + MBP (not shown). Non-parametrical Kruskal Wallis multiple group comparison test was used followed by Dunns test for differences between groups. Significant differences with the control condition are indicated with asterisks: ${ }^{*} P \leq 0.05,{ }^{*} P \leq 0.01,{ }^{* *} P \leq 0.001$. IFN interferon, MBP myelin basic protein, $N O$ nitric oxide

period (Fig. 7b). This finding indicates that the effect of soluble factors secreted by rMAPC is actually protective and does not induce an excessive proliferation resulting in higher cell numbers. Next, we further characterized the behavior of rMAPC in the in vitro generated neurodegenerative environment. We analyzed the mRNA expression of neurotrophic factors known to enhance the survival and proliferation of oligodendrocytes and oligodendrocytes progenitors, as well as those that enhance myelin formation [44, 52-55]. We demonstrate that rMAPC when cultured in supernatant derived from sublethally damaged OLN93 cells $\left(\mathrm{OLN}-\mathrm{CM}_{\mathrm{H} 2 \mathrm{O} 2}\right)$ upregulate the expression of the neurotrophic factors $V E G F \alpha$ and CNTF but not GDNF (Fig. 7c). HGF was not detected under any condition. Collectively, these results indicate that the interaction with neurodegenerative signals derived by damaged oligodendrocytes enhances the neuroprotective features of rMAPC.

\section{Discussion}

Stem cell transplantation represents a promising therapeutic approach to treat neuroinflammatory and neurodegenerative disorders such as MS, TBI, SCI and stroke. In this study, we show that rMAPC, a stem cell population similar but distinct to MSCs, possess immunomodulatory and neuroprotective properties which are further enhanced when challenged with selected neuroinflammatory stimuli. These findings point out that MAPC can be considered as a promising therapeutic option for neuroinflammatory and neurodegenerative disorders.

In concordance with other studies, rMAPC exhibit a low immunogenic profile, being negative for costimulatory molecules and RT-1b. Expression of RT-1a, though, makes rMAPC prone to lysis by NK cells in case 


\section{A}

\section{T cell proliferation}

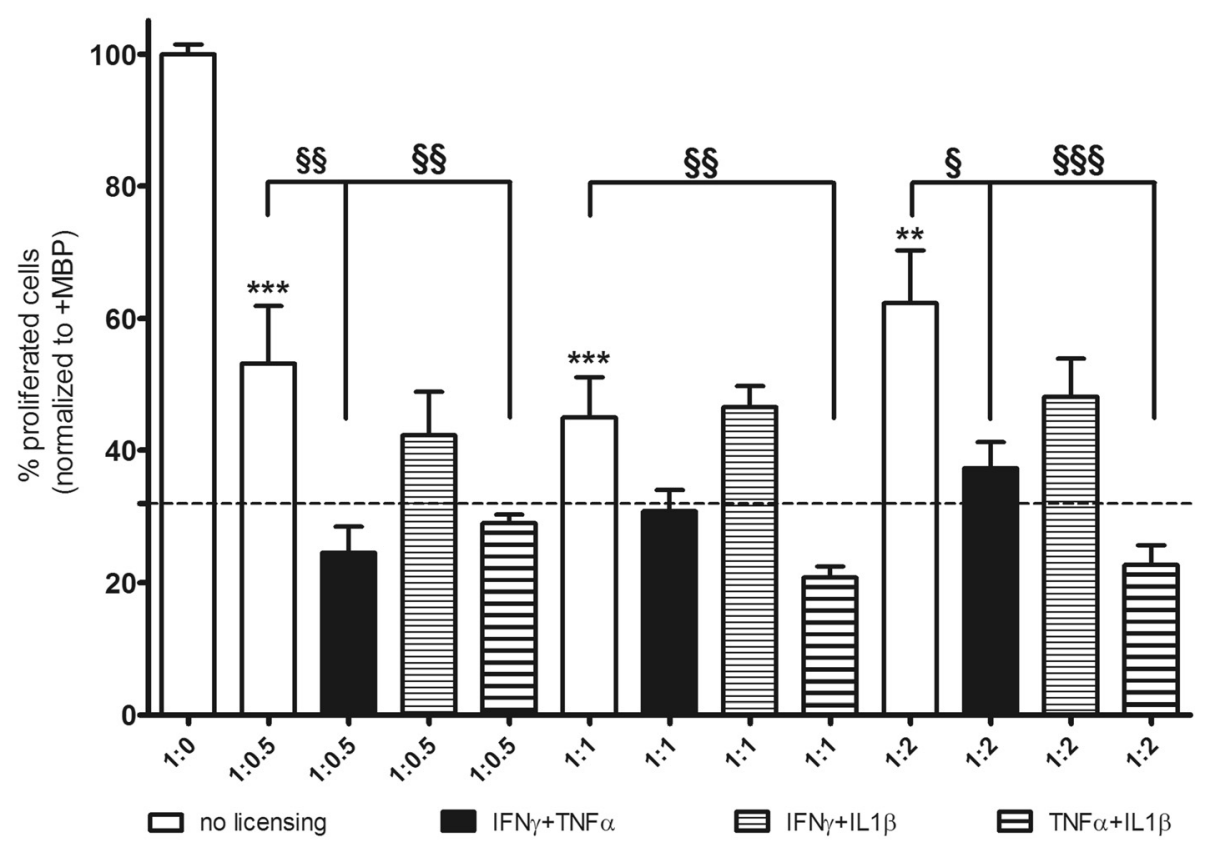

B

Inhibition of immunomodulation (IFN $\gamma+$ TNF $\alpha$ )

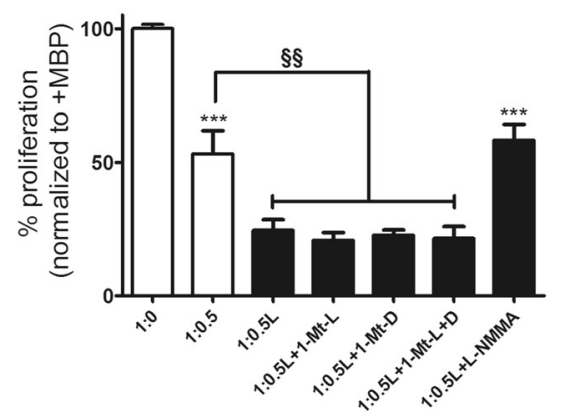

C

\section{Inhibition of immunomodulation}

$(\mathrm{TNF} \alpha+\mathrm{IL} 1 \beta)$

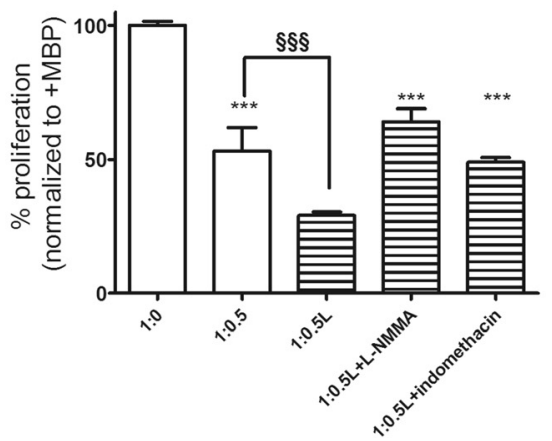

Fig. 4 Inflammatory licensing of rMAPC leads to enhanced T-cell suppression. a Co-cultures of T cells with rMAPC in the presence of MBP, where rMAPC were either pre-treated or not (white bars) with different combinations of pro-inflammatory cytokines (IFNy + TNFa, IFNY + IL1 $\beta$, TNFa + IL1 $\beta$ ). Negative control (T cells without MBP) is shown as a dotted line. Asterisks indicate statistical significance compared to the positive control (1:0, T cells + MBP). Paragraph signs ( $($ ) indicate the statistical significance between the pre-treated (assigned bars) and non-treated (white bars) corresponding ratios. $\mathbf{b}$ Application of inhibitors in the co-culture (1:0.5 ratio) after IFNY + TNFa pre-treatment (black bars). Significant differences compared to the positive control (1:0, T cells + MBP) are shown with asterisks. Paragraph signs ( $\S$ ) show differences with the non-pre-treated 1:0.5 ratio (white bar). c Application of inhibitors in the co-culture (1:0.5 ratio) after TNFa + IL1 $\beta$ pre-treatment (striped bars). Significant differences compared to the positive control (1:0, T cells + MBP) are shown with asterisks. Paragraph signs ( $($ ) show differences with the non-pre-treated 1:0.5 ratio (white bar). Results are shown as mean percentages \pm SEM of proliferation normalized to the positive control $(1: 0, T$ cells $+\mathrm{MBP})$, from three independent experiments, with triplicates per experiment. Data were analyzed with non-parametrical Kruskal Wallis multiple group comparison test, followed by Dunns for differences between the groups. ${ }^{*} P \leq 0.05$, ${ }^{* *} P \leq 0.01,{ }^{* * *} P \leq 0.001 ;{ }^{\S} P \leq 0.05,{ }^{\S \S} P \leq 0.01,{ }^{\S \S \S} P \leq 0.001$. 1-Mt-D 1-methyl-dextrotryptophan, 1-Mt-L 1-methyl-levo-tryptophan, IFN interferon, IL interleukin, L-NMMA L-N ${ }^{G}$-monomethyl arginine citrate, MBP myelin basic protein, TNF tumor necrosis factor

of transplantation as hMAPC [22]. The low immunogenic profile of rMAPC was further confirmed by the low, if any, increase of pro-inflammatory genes following licensing. Upregulation of TNF $\alpha$ by rMAPC should be investigated further, although TNF $\alpha$ can also act as an inhibitory mechanism for CD4 T-cell proliferation [56]. 


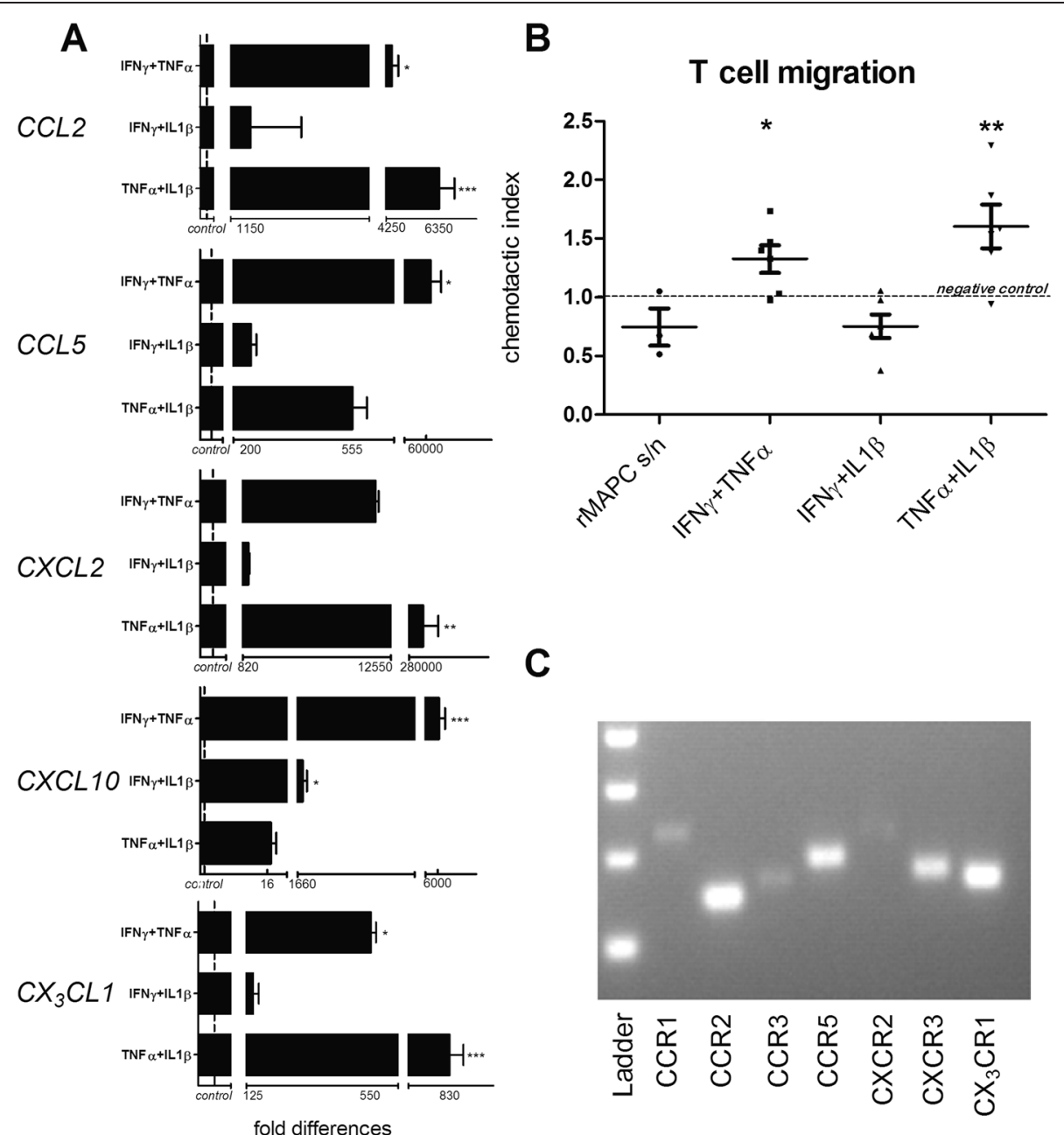

Fig. 5 Inflammatory treatment enhances the chemoattractive activity of rMAPC. a Gene expression of chemokines by rMAPC following inflammatory treatment. Fold differences compared to control (PBS treated, dotted line) are shown. Significant differences with the control condition are indicated with asterisks. Values represent mean \pm SEM from five independent experiments. b Migration of MBP-specific T cells towards supernatants derived from licensed rMAPC (with defined cytokines combinations). Chemotactic index is shown, which is calculated by dividing the number of migrated T cells per condition by the number of migrated $T$ cells of the negative control (non-conditioned medium). Results are from three independent experiments, with duplicates per experiment. c Detection of chemokine receptor mRNA expression in MBP-specific T cells. The genes selected have as ligands the chemokines upregulated in panel $\mathbf{a}$. The picture is a representative experiment out of a total of three independent experiments. Non-parametrical Kruskal Wallis multiple groups comparison test was used followed by Dunns test for differences between groups. Significant differences with the control condition are indicated with asterisks: ${ }^{*} P \leq 0.05,{ }^{* *} P \leq 0.01,{ }^{* * *} P \leq 0.001$. IFN interferon, IL interleukin, $r M A P C$ s $/ n$ supernatant derived by naïve (non-treated) rat multipotent adult progenitor cells, TNF tumor necrosis factor

Human and rodent MAPC have been reported to inhibit T-cell proliferation after polyclonal stimulation or allogeneic responses [21, 57, 58]. We demonstrate here that rMAPC effectively suppress proliferation of myelinreactive $\mathrm{T}$ cells in vitro and that licensing enhances the suppressive effect of rMAPC. This finding suggests that transplanted MAPC can suppress the autoantigenspecific adaptive inflammatory response in MS. In line with other studies with hMAPC, rMAPC suppressed IFN $\gamma$ release from autoreactive $\mathrm{T}$ cells in co-culture, indicating an attenuation of Th1 polarization [57].
CNS neurodegeneration and peripheral inflammation represent microenvironments that potentially affect the behavior of transplanted cells. We show that proinflammatory cytokines markedly increased the expression of immunomodulatory markers previously reported for MSCs and hMAPC, such as iNOS, Ido-1, PD-L1, TSG-6 and prostaglandin E2 (PGE $)$ [23, 39, 40, 42, 43, $59,60]$. IFN $\gamma$-driven upregulation of these molecules in MAPC and MSCs collectively has been demonstrated $[23,24,40,41,43,57]$. We now provide evidence that a combination of inflammatory cytokines and, in particular, 


\section{A

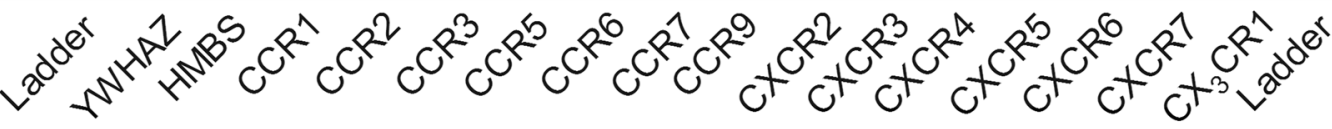

B

Migration of rMAPC

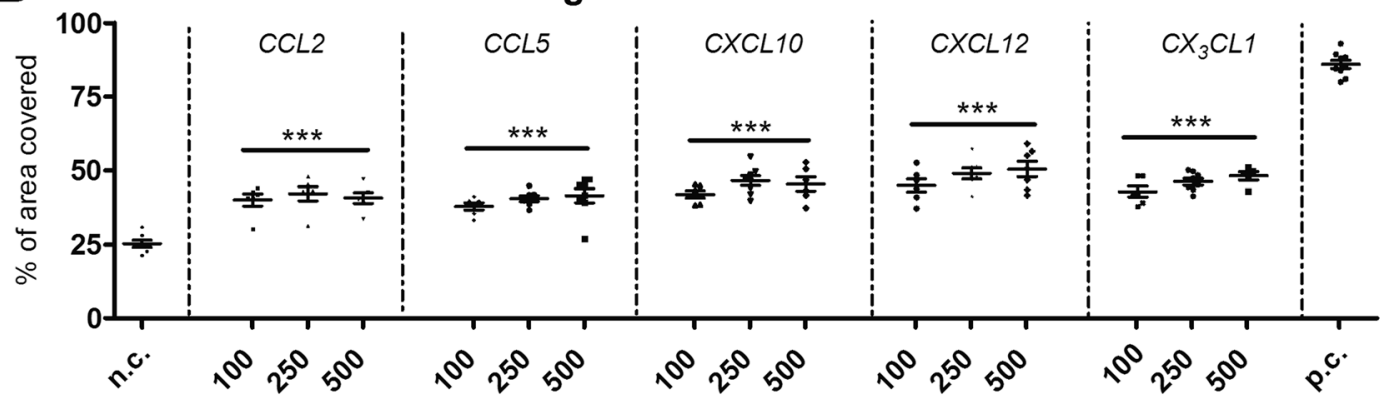

C
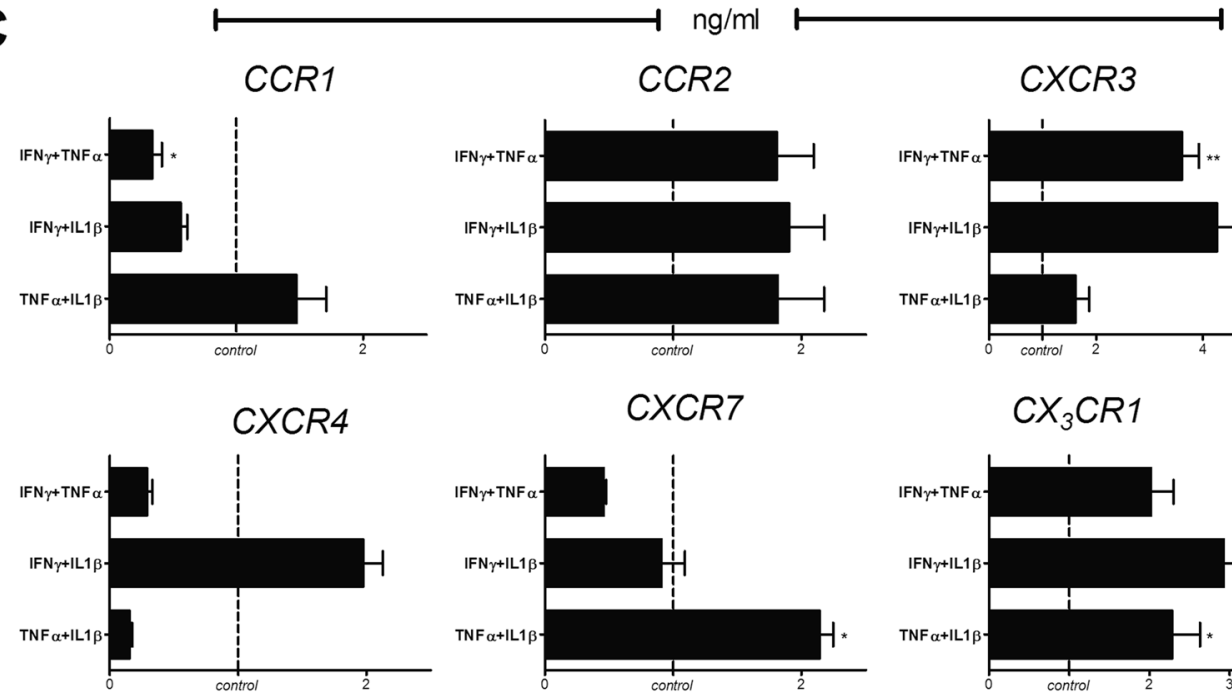

CXCR7
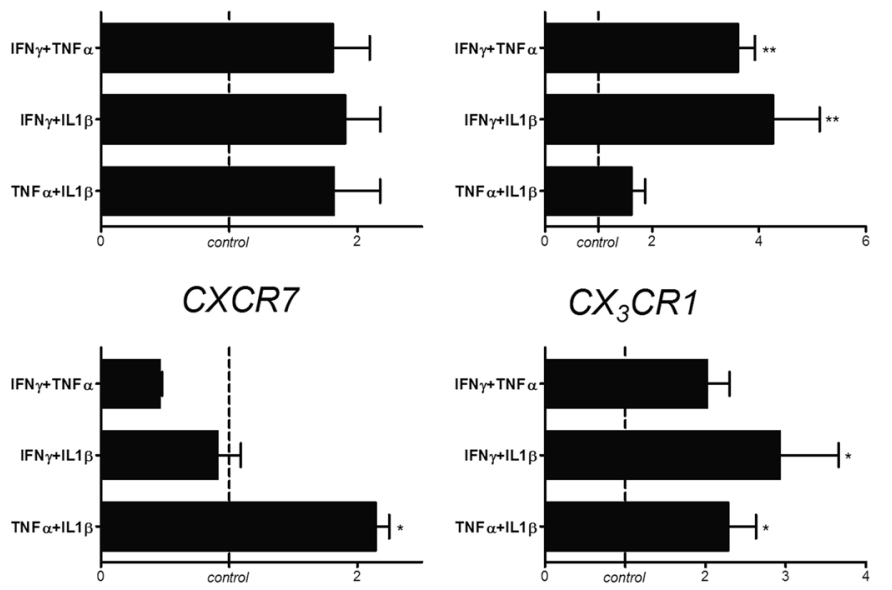

Migration of rMAPC after licensing

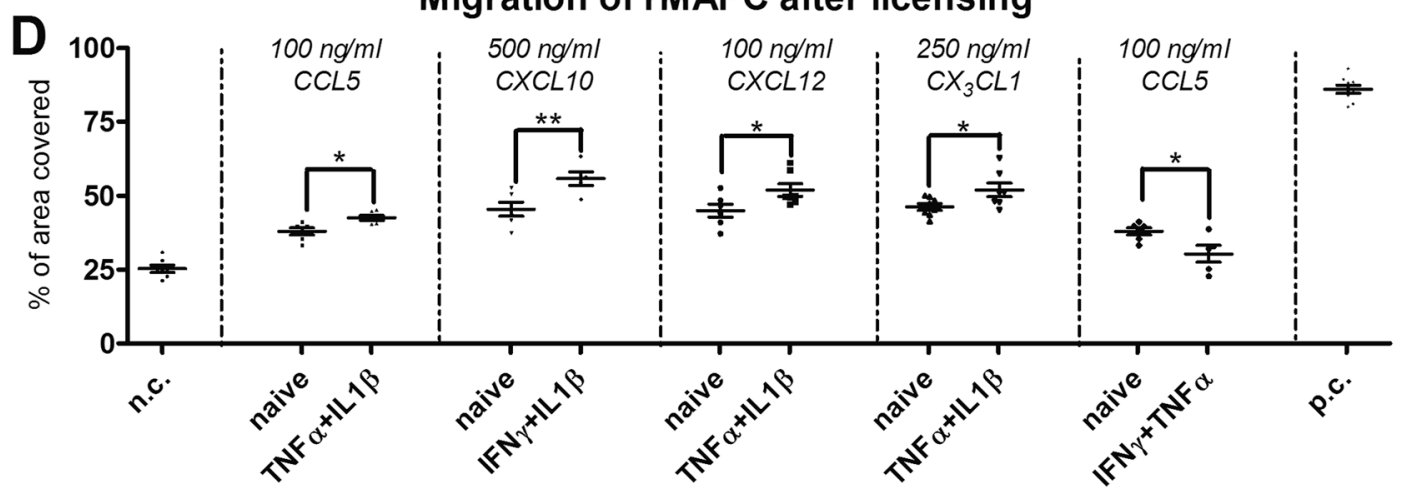

Fig. 6 (See legend on next page.) 
(See figure on previous page.)

Fig. 6 rMAPC migration is altered following licensing. a Detection of chemokine receptor mRNA in rMAPC. Amplified cDNAs are visualized in a $1.5 \%$ agarose gel. YWHAZ and HMBS were used as loading controls. One representative experiment out of five is shown. b rMAPC migration towards important MS pathogenesis chemokines. Three different concentrations of chemokines were used in the lower compartment (100, 250 and $500 \mathrm{ng} / \mathrm{ml})$. The percentage of area covered by the migrated cells is shown. Values represent mean \pm SEM from four independent experiments, with duplicates per experiment. Asterisks show statistical significance between the different concentrations of each chemokine and the negative control. No statistically significant differences were found between the different concentrations for each chemokine. Positive control values showed statistically significant differences with all the other conditions. Data were analyzed with one way analysis of variance comparison test, followed by Dunnett's test for differences between the groups. c Gene expression of chemokine receptors by rMAPC following inflammatory treatment. Fold differences compared to control (PBS treated, dotted line) are shown. Significant differences with the control condition are indicated with asterisks. Values represent mean \pm SEM from five independent experiments. $\mathbf{d}$ rMAPC migration following 12 hours of cytokine pre-treatment. Three different concentrations of chemokines were used in the lower compartment (100,250 and $500 \mathrm{ng} / \mathrm{ml})$. Only the statistically significant changes are shown here. The percentage of area covered by the migrated cells is shown. Values represent mean \pm SEM from four independent experiments, with duplicates per experiment. Asterisks show the statistical significant difference between the pre-treated and not treated (naïve) migrated fraction towards specific concentrations of each chemokine. All values differ significantly with n.c. Mean of positive control is statistically significant to all the other conditions. Data were analyzed with one way analysis of variance comparison test, followed by Dunnett's test for differences between the groups. ${ }^{*} P \leq 0.05,{ }^{* *} P \leq 0.01,{ }^{* *} P \leq 0.001$. IFN interferon, IL interleukin, $n$.c. negative control, $p$.c. positive control, rMAPC rat multipotent adult progenitor cells, TNF tumor necrosis factor

\section{A}

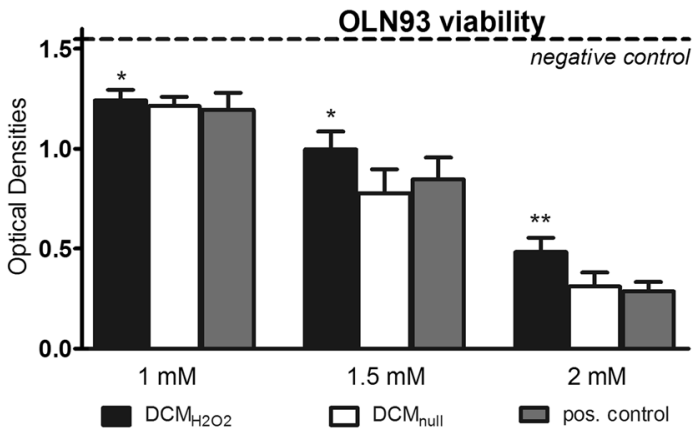

B

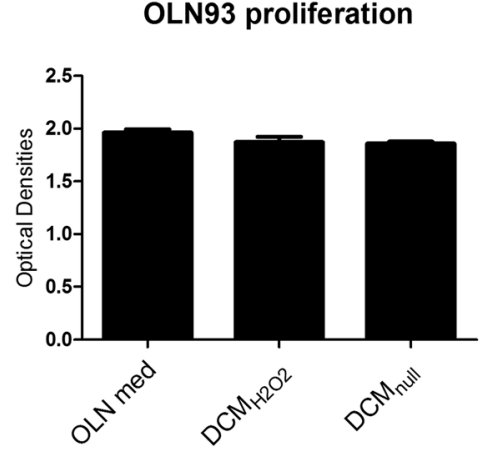

GDNF
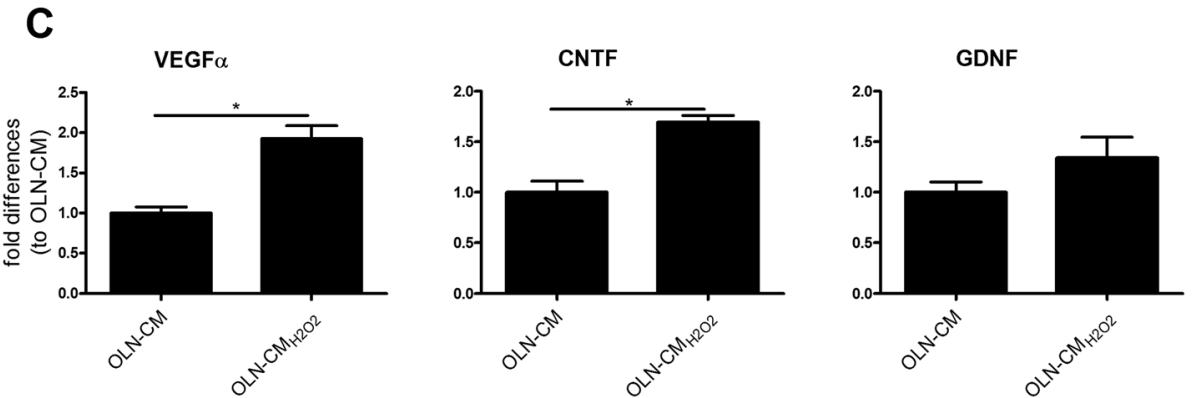

Fig. 7 Neurodegeneration enhances the neuroprotective features of rMAPC. a Neuroprotection assay where OLN93 cells were pre-treated (with the indicated (double) conditioned media and then three concentrations of $\mathrm{H}_{2} \mathrm{O}_{2}$ were added (pos. control). Optical densities are shown ( \pm SEM) from five experiments. Negative control (dotted line) represents OLN93 cells without damage insult. One way analysis of variance followed by Dunnet's test for multiple comparisons between groups was used. b OLN93 cells were pre-treated for 5 hours with rMAPC double conditioned media (DCM) and then allowed to proliferate for 24 hours. Optical densitites are shown $( \pm S E M), n=5$ experiments. c rMAPC gene expression of neurotrophic factors (VEGFa, CNTF, GDNF) when treated with OLN-CM $\mathrm{H} 2 \mathrm{O} 2_{2}$ and OLN-CM. Expressions were relatively quantified against the expression of YWHAZ and CyCA. The fold differences are shown in comparison to OLN-CM ( \pm SEM) from five experiments. Mann Whitney $t$-test was used for comparisons between two groups. Significant differences are shown with asterisks: ${ }^{*} P \leq 0.05,{ }^{* *} P \leq 0.01,{ }^{* * *} P \leq 0.001$. CM conditioned medium, CNTF ciliary neurotrophic factor, GDNF glial cell line-derived neurotrophic factor, OLN med OLN93 medium, VEGF vascular endothelial growth factor 
the combinations of IFN $\gamma / \mathrm{TNF} \alpha$ and TNF $\alpha / \mathrm{IL} 1 \beta$ induce the increase of iNOS, TSG-6 and COX-2 mRNA transcripts. We demonstrate that the increase of $\mathrm{NO}$ and $\mathrm{PGE}_{2}$ is functionally involved in the suppression of T-cell proliferation by licensed rMAPC as suppression was abrogated when iNOS and COX-2 were inhibited in the cocultures.

While PGE2 has already been reported to partially underlie the suppressive effect of mMAPC on T-cell proliferation [21, 41], we now provide evidence that $\mathrm{NO}$ is crucial in this process as well. Notably, other studies using mMAPC have excluded $\mathrm{PGE}_{2}$ and $\mathrm{NO}$ as possible mechanisms for the modulation of alloreactive T-cell responses [21, 61]. Moreover, human and rat MAPC have been reported to modulate alloreactive T-cell responses by an Ido-dependent mechanism $[57,58]$. Jacobs et al. showed that IFN $\gamma$ pre-treatment of hMAPC did not confer an additional suppressive effect as it was already of a great extent without pre-licensing [57]. Overall, there is a pluripotency and species-related variation regarding the mechanisms involved in T-cell suppression, as is apparent for MSCs as well [62, 63].

We found that licensing of rMAPC markedly increased the expression of a large number of chemokines, such as CXCL2, CXCL10, CCL2, CCL5 and fractalkine. These chemokines are well known for their ability to attract encephalitogenic $\mathrm{CD}^{+} \mathrm{T}$ cells in the context of neuroinflammation [64-67], as well as CD8+ $\mathrm{T}$ cells [68]. The ability of stem cells to migrate towards inflammatory chemokines and to attract leukocytes is a crucial aspect of their potential therapeutic use. For instance, an IFN $\gamma$-mediated increase in chemokine release by murine MSCs, such as CXCL10, is key to their immunomodulatory properties [43]. In line with this chemoattractive transcriptional profile, we demonstrated that rMAPC effectively attracted myelin-specific $\mathrm{T}$ cells, especially when challenged with IFN $\gamma+\mathrm{TNF} \alpha$ and TNF $\alpha+$ IL1 $\beta$. In this project we only assessed the capacity of rMAPC to attract $\mathrm{T}$ cells. Others have shown that licensing enhances the chemoattractive ability of human MSCs towards other immune cells and, mainly, neutrophils [69]. Future studies should determine whether MAPC also attract other immune cell subsets that play an important role in inflammatory pathophysiology, such as monocytes and dendritic cells. Increased attraction of other immune cell types such as macrophages, for instance, would be crucial for the immunomodulatory mechanisms of MAPC, as it has already been demonstrated that hMAPC suppress their classically activated phenotype in vivo [18].

In addition to their ability to attract $\mathrm{T}$ cells, we characterized rMAPC regarding their migratory profile. We observed that rMAPC were able to migrate towards chemokines typical for a neuroinflammatory environment. Of interest, the motility of rMAPC towards these chemokines was further enhanced following licensing, except of the CCL2/CCR1 interaction following IFN $\gamma+$ TNF $\alpha$ treatment. Overall, these results point out the potential of rMAPC in transplantation experiments where inflammation is already established. Directed injection of NSCs within the CNS in the EAE model showed that inflammation triggered the migration of the transplanted cells towards the white matter tracts, with CXCL12 $\alpha$ and CCL2 being important inflamed tissue-derived chemoattractive stimuli [70]. Furthermore, in other neuroinflammatory models, both peripheral- and CNStargeted injected stem cells are being attracted by local sites of inflammation [71]. While the lack of expression of CCR7 could limit the migration of rMAPC to lymphoid organs, previously reported experimental set up with intravenous administration of hMAPC showed no real obstacle [19]. This points out that other molecules in addition to chemokine receptors are implicated [72]. Overall, these features highlight the migratory potential of rMAPC when injected either in the periphery or within the CNS.

MSCs and NSCs possess neuroprotective features which are induced from inflamed CNS microenvironment $[4,34]$. Our findings show that rMAPC that are exposed to sublethally damaged OLN93 cells gain neuroprotective properties. This suggests that damaged oligodendrocytes release mediators that promote the neuroprotective capacity of rMAPC. Similar findings have been reported for rat MSCs [34]. The fact that rMAPC increase their expression of trophic factors confirms this notion. It has already been suggested that human and rodent MAPC provide neuroprotection and vascular regeneration in vivo through the secretion of trophic factors [73-75]. Oligodendrocytes in normal appearing white matter (NAWM) seem to actively participate in immune regulation within the CNS during MS pathology as they are elevating the expression of transcription factors such as STAT-6 and STAT-4, which are important for the activation of anti- and proinflammatory pathways, respectively [76]. IL-4 and IL1 $\beta$, which have been detected in oligodendrocytes in MS NAWM, could prime rMAPC in the same way as do the combinations of pro-inflammatory cytokines. In this way, rMAPC could be effectively triggered by damaged oligodendrocytes or even neurons to secrete trophic factors and thus provide neuroprotection.

\section{Conclusions}

MAPC possess the required properties needed to consider the development of a therapeutic scheme for neuroinflammatory disorders such as MS, TBI and $\mathrm{SCI}$, as was established previously for MSCs $[6,7,77]$. We show that rMAPC are lowly immunogenic and possess numerous potential mechanisms which could facilitate MAPC 
action, even if they cannot transdifferentiate towards damaged CNS cells. While the microenvironment in neuroinflammatory disorders is likely more complex, we show that typical pro-inflammatory cytokines and mediators released by damaged oligodendrocytes strongly enhance the immunomodulatory properties of rMAPC. Apart from affecting $\mathrm{T}$ cells and oligondendrocytes, MAPC may also affect other immune and CNS-resident cell types that are important drivers of neuroinflammation, such as macrophages, microglia and astrocytes. Future studies should define the impact of (licensed) rMAPC on these cell types. Collectively, our findings suggest that MAPC represent an interesting therapeutic tool for the treatment of neuroinflammatory disorders. Yet, future experiments should reinforce the notion that MAPC can reduce neuroinflammation and neurodegeneration in animal models of MS, TBI and SCI [18-20].

\section{Additional files}

Additional file 1: Selection of suitable positive control for migration assays. (TIFF $274 \mathrm{~kb}$ )

Additional file 2: Schematic illustration of the generation of double conditioned media and the neuroprotection assay. (TIFF $55 \mathrm{~kb}$ ) Additional file 3: Sequences of primers used for quantitative PCR. (DOCX $18 \mathrm{~kb}$ )

Additional file 4: rMAPC gene expression analysis following inflammatory treatment with real-time PCR. (DOCX $15 \mathrm{~kb}$ )

Additional file 5: Antigen-specific proliferation of $\mathrm{T}$ cells is not affected by the inhibitors alone. (TIFF $3085 \mathrm{~kb}$ )

\footnotetext{
Abbreviations

1-Mt-D: 1-methyl-dextro-tryptophan; 1-Mt-L: 1-methyl-levo-tryptophan; 7AAD: 7 aminoactinomycin D; BSA: Bovine serum albumin; CCL: Chemokine (C-C motif) ligand; CCR: Chemokine (C-C motif) receptor; CD: Cluster of differentiation; CDNA: Complementary deoxyribonucleic acid; CFSE: Carboxyfluorescein succinimidyl ester; CM: Conditioned medium; CNS: Central nervous system; CNTF: Ciliary neurotrophic factor; COX: Cyclooxygenase; CXCL: Chemokine (C-X-C motif) ligand; CXCR: Chemokine (C-X-C motif) receptor; CyCA: Cyclophilin A; DCM: Double conditioned medium; DMEM: Dulbecco's modified Eagle's medium; DMSO: Dimethyl sulfoxide; EAE: Experimental autoimmune encephalomyelitis; FACS: Fluorescence-activated cell sorting; FCS: Fetal calf serum; GDNF: Glial cell line-derived neurotrophic factor; $\mathrm{H}_{2} \mathrm{O}_{2}$ : Hydrogen peroxide, HGF, Hepatocyte growth factor; hMAPC: Human multipotent adult progenitor cells; HMBS: Hydroxymethylbilane synthase; HO-1: Heme oxygenase 1; Ido-1: ilndoleamine 2,3-dioxygenase 1; IFNy: interferon gamma; IL1B: Interleukin-1 beta; iNOS: Inducible nitric oxide synthase; L-NMMA: L-N ${ }^{G}-$ monomethyl arginine citrate; MAPC: Multipotent adult progenitor cells; MBP: Myelin basic protein; mMAPC: Murine multipotent adult progenitor cells; mRNA: Messenger ribonucleic acid; MS: Multiple sclerosis; MSC: Mesenchymal stem cell; MTT: 3-(4,5)-dimethylthiazol-(-z-y1)-3, 5-diphenytetrazoliumronide; NAWM: Normal appearing white matter; NK: Natural killer; NO: Nitric oxide; NSC: Neural stem cell; PBS: Phosphatebuffered saline; PD-L1: Programmed death-ligand 1; PFA: Paraformaldehyde; $\mathrm{PGE}_{2}$ : Prostaglandin E2; rMAPC: Rat multipotent adult progenitor cells; RPMI: Roswell Park Memorial Institute; RT-PCR: Real time polymerase chain reaction; SCl: Spinal cord injury; SEM: Standard error of the mean; TBI: Traumatic brain injury; TNFa: Tumor necrosis factor alpha; TSG-6: TNF-stimulated gene 6 protein; VEGFa: Vascular endothelial growth factor alpha; YWHAZ: 14-3-3 protein zeta/delta.
}

\section{Competing interests}

DC, KG and JP are employees of ReGenesys BVBA, the European subsidiary of Athersys Inc. RWM and RD are employees of Athersys Inc. The other authors declare that they have no competing interests.

\section{Authors' contributions}

SR performed the experiments and wrote the manuscript. SR, JFJB and NH designed the experiments. SR, JFJB and RD performed the analysis of data. $D C, K G$ and JP contributed to the design of the experiments. DC, RWM, RD, $\mathrm{KG}, \mathrm{PS}$ and JP revised the manuscript for important intellectual content. RWM, RD, AB and PS contributed to data interpretation and editing of the manuscript. $\mathrm{AB}$ contributed to the design and interpretation of migration assays. JFJB and $\mathrm{NH}$ revised the manuscript. All authors read and approved the final manuscript.

\section{Acknowledgements}

The authors would like to thank Ms. Katrien Wauterickx, Ms. Christel Bocken and Mr. Jo Janssen (Hasselt University, Biomedical Research institute) for overall technical assistance. Additionally, we gratefully thank Ms. Ellen Van Houtven (ReGenesys) for her assistance in designing the migration assays. This research was supported by the Belgian Charcot Foundation.

\section{Author details}

${ }^{1}$ Hasselt University, Biomedical Research Institute/Transnational University Limburg, School of Life Sciences, Campus Diepenbeek, Agoralaan building C, 3590 Diepenbeek, Belgium. ${ }^{2}$ ReGenesys BVBA, Leuven, Belgium. ${ }^{3}$ Department of Regenerative Medicine, Athersys Inc., Cleveland, OH, USA.

Received: 22 May 2015 Revised: 26 August 2015

Accepted: 26 August 2015 Published online: 16 September 2015

\section{References}

1. Einstein $\mathrm{O}$, Fainstein N, Vaknin I, Mizrachi-Kol R, Reihartz E, Grigoriadis N, et al. Neural precursors attenuate autoimmune encephalomyelitis by peripheral immunosuppression. Ann Neurol. 2007;61:209-18.

2. Gerdoni E, Gallo B, Casazza S, Musio S, Bonanni I, Pedemonte E, et al. Mesenchymal stem cells effectively modulate pathogenic immune response in experimental autoimmune encephalomyelitis. Ann Neurol. 2007:61:219-27.

3. Kassis I, Grigoriadis N, Gowda-Kurkalli B, Mizrachi-Kol R, Ben-Hur T, Slavin S, et al. Neuroprotection and immunomodulation with mesenchymal stem cells in chronic experimental autoimmune encephalomyelitis. Arch Neurol. 2008;65:753-61.

4. Pluchino S, Quattrini A, Brambilla E, Gritti A, Salani G, Dina G, et al. Injection of adult neurospheres induces recovery in a chronic model of multiple sclerosis. Nature. 2003;422:688-94.

5. Pluchino S, Zanotti L, Rossi B, Brambilla E, Ottoboni L, Salani G, et al. Neurosphere-derived multipotent precursors promote neuroprotection by an immunomodulatory mechanism. Nature. 2005;436:266-71.

6. Anbari F, Khalili MA, Bahrami AR, Khoradmehr A, Sadeghian F, Fesahat F, et al. Intravenous transplantation of bone marrow mesenchymal stem cells promotes neural regeneration after traumatic brain injury. Neural Regen Res. 2014:9:919-23.

7. Wilcox JT, Satkunendrarajah K, Zuccato JA, Nassiri F, Fehlings MG. Neural precursor cell transplantation enhances functional recovery and reduces astrogliosis in bilateral compressive/contusive cervical spinal cord injury. Stem Cells Transl Med. 2014;3:1148-59.

8. Zhang R, Liu Y, Yan K, Chen L, Chen XR, Li P, et al. Anti-inflammatory and immunomodulatory mechanisms of mesenchymal stem cell transplantation in experimental traumatic brain injury. J Neuroinflammation. 2013;10:106.

9. Jacobs SA, Roobrouck VD, Verfaillie CM, Van Gool SW. Immunological characteristics of human mesenchymal stem cells and multipotent adult progenitor cells. Immunol Cell Biol. 2013;91:32-9.

10. Sindberg GM, Lindborg BA, Wang Q, Clarkson C, Graham M, Donahue R, et al. Comparisons of phenotype and immunomodulatory capacity among rhesus bone-marrow-derived mesenchymal stem/stromal cells, multipotent adult progenitor cells, and dermal fibroblasts. J Med Primatol. 2014:43:231-41.

11. Prockop DJ, Olson SD. Clinical trials with adult stem/progenitor cells for tissue repair: let's not overlook some essential precautions. Blood. 2007;109:3147-51. 
12. Karussis D, Karageorgiou C, Vaknin-Dembinsky A, Gowda-Kurkalli B, Gomori $J M$, Kassis I, et al. Safety and immunological effects of mesenchymal stem cell transplantation in patients with multiple sclerosis and amyotrophic lateral sclerosis. Arch Neurol. 2010;67:1187-94.

13. Yamout B, Hourani R, Salti H, Barada W, El-Hajj T, Al-Kutoubi A, et al. Bone marrow mesenchymal stem cell transplantation in patients with multiple sclerosis: a pilot study. J Neuroimmunol. 2010;227:185-9.

14. Jiang $Y$, Jahagirdar BN, Reinhardt RL, Schwartz RE, Keene CD, Ortiz-Gonzalez $X R$, et al. Pluripotency of mesenchymal stem cells derived from adult marrow. Nature. 2002;418:41-9.

15. Subramanian K, Geraerts M, Pauwelyn KA, Park Y, Owens DJ, Muijtjens M, et al. Isolation procedure and characterization of multipotent adult progenitor cells from rat bone marrow. Methods Mol Biol. 2010;636:55-78.

16. Ulloa-Montoya F, Kidder BL, Pauwelyn KA, Chase LG, Luttun A, Crabbe A, et al. Comparative transcriptome analysis of embryonic and adult stem cells with extended and limited differentiation capacity. Genome Biol. 2007;8:R163.

17. Yasuhara T, Hara K, Maki M, Mays RW, Deans RJ, Hess DC, et al. Intravenous grafts recapitulate the neurorestoration afforded by intracerebrally delivered multipotent adult progenitor cells in neonatal hypoxic-ischemic rats. J Cereb Blood Flow Metab. 2008;28:1804-10.

18. Walker PA, Bedi SS, Shah SK, Jimenez F, Xue H, Hamilton JA, et al. Intravenous multipotent adult progenitor cell therapy after traumatic brain injury: modulation of the resident microglia population. J Neuroinflammation. 2012;9.

19. Walker PA, Shah SK, Jimenez F, Gerber MH, Xue H, Cutrone R, et al. Intravenous multipotent adult progenitor cell therapy for traumatic brain injury: preserving the blood brain barrier via an interaction with splenocytes. Exp Neurol. 2010;225:341-52.

20. Bedi SS, Hetz R, Thomas C, Smith P, Olsen AB, Williams S, et al. Intravenous multipotent adult progenitor cell therapy attenuates activated microglial/ macrophage response and improves spatial learning after traumatic brain injury. Stem Cells Transl Med. 2013;2:953-60.

21. Luyckx A, De Somer L, Jacobs S, Rutgeerts O, Lenaerts C, Roobrouck VD, et al. Oct4-negative multipotent adult progenitor cells and mesenchymal stem cells as regulators of T-cell alloreactivity in mice. Immunol Lett. 2011;137:78-81.

22. Jacobs SA, Plessers J, Pinxteren J, Roobrouck VD, Verfaillie CM, Van Gool SW. Mutual interaction between human multipotent adult progenitor cells and NK cells. Cell Transplant. 2014;23:1099-110.

23. Krampera M. Mesenchymal stromal cell 'licensing': a multistep process. Leukemia. 2011;25:1408-14.

24. English K, Barry FP, Field-Corbett CP, Mahon BP. IFN-gamma and TNF-alpha differentially regulate immunomodulation by murine mesenchymal stem cells. Immunol Lett. 2007;110:91-100.

25. Sheng $H$, Wang $Y$, Jin $Y$, Zhang $Q$, Zhang $Y$, Wang $L$, et al. A critical role of IFNgamma in priming MSC-mediated suppression of $T$ cell proliferation through up-regulation of B7-H1. Cell Res. 2008;18:846-57.

26. Croitoru-Lamoury J, Lamoury FM, Zaunders JJ, Veas LA, Brew BJ. Human mesenchymal stem cells constitutively express chemokines and chemokine receptors that can be upregulated by cytokines, IFN-beta, and Copaxone. J Interferon Cytokine Res. 2007;27:53-64.

27. di Penta A, Moreno B, Reix S, Fernandez-Diez B, Villanueva M, Errea O, et al. Oxidative stress and proinflammatory cytokines contribute to demyelination and axonal damage in a cerebellar culture model of neuroinflammation. Plos One. 2013;8:e54722

28. Filion LG, Graziani-Bowering G, Matusevicius D, Freedman MS. Monocyte-derived cytokines in multiple sclerosis. Clin Exp Immunol. 2003;131:324-34

29. Lovett-Racke AE, Yang Y, Racke MK. Th1 versus Th17: are T cell cytokines relevant in multiple sclerosis? Biochim Biophys Acta. 2011;1812:246-51.

30. Zhao R, Zhou H, Su SB. A critical role for interleukin-1 beta in the progression of autoimmune diseases. Int Immunopharmacol. 2013;17:658-69.

31. Bogie JF, Stinissen P, Hellings N, Hendriks JJ. Myelin-phagocytosing macrophages modulate autoreactive $T$ cell proliferation. $J$ Neuroinflammation. 2011;8:85.

32. Bronckaers A, Hilkens P, Fanton Y, Struys T, Gervois P, Politis C, et al. Angiogenic properties of human dental pulp stem cells. Plos One. 2013;8:e71104.

33. Schneider CA, Rasband WS, Eliceiri KW. NIH image to ImageJ: 25 years of image analysis. Nat Methods. 2012;9:671-5.

34. Isele NB, Lee HS, Landshamer S, Straube A, Padovan CS, Plesnila N, et al. Bone marrow stromal cells mediate protection through stimulation of PI3-K/Akt and MAPK signaling in neurons. Neurochem Int. 2007:50:243-50.
35. Untergasser A, Cutcutache I, Koressaar T, Ye J, Faircloth BC, Remm M, et al. Primer3-new capabilities and interfaces. Nucleic Acids Res. 2012;40, e115.

36. Livak KJ, Schmittgen TD. Analysis of relative gene expression data using real-time quantitative PCR and the 2(-Delta Delta C(T)) method. Methods. 2001;25:402-8

37. Vandesompele J, De Preter K, Pattyn F, Poppe B, Van Roy N, De Paepe A, et al. Accurate normalization of real-time quantitative RT-PCR data by geometric averaging of multiple internal control genes. Genome Biol. 2002;3:RESEARCH0034

38. GraphPad Prism Software. www.graphpad.com.

39. Augello A, Tasso R, Negrini SM, Amateis A, Indiveri F, Cancedda R, et al. Bone marrow mesenchymal progenitor cells inhibit lymphocyte proliferation by activation of the programmed death 1 pathway. Eur J Immunol. 2005;35:1482-90.

40. Donders R, Vanheusden M, Bogie JF, Ravanidis S, Thewissen K, Stinissen P, et al. Human Wharton's jelly-derived stem cells display immunomodulatory properties and transiently improve rat experimental autoimmune encephalomyelitis. Cell Transplant. 2014

41. Highfill SL, Kelly RM, O'Shaughnessy MJ, Zhou Q, Xia L, Panoskaltsis-Mortari A, et al. Multipotent adult progenitor cells can suppress graft-versus-host disease via prostaglandin E2 synthesis and only if localized to sites of allopriming. Blood. 2009;114:693-701.

42. Kota DJ, Wiggins LL, Yoon N, Lee RH. TSG-6 produced by hMSCs delays the onset of autoimmune diabetes by suppressing Th1 development and enhancing tolerogenicity. Diabetes. 2013;62:2048-58.

43. Ren GW, Zhang LY, Zhao X, Xu GW, Zhang YY, Roberts Al, et al. Mesenchymal stem cell-mediated immunosuppression occurs via concerted action of chemokines and nitric oxide. Cell Stem Cell. 2008;2:141-50.

44. Bai L, Lennon DP, Caplan Al, DeChant A, Hecker J, Kranso J, et al. Hepatocyte growth factor mediates mesenchymal stem cell-induced recovery in multiple sclerosis models. Nat Neurosci. 2012;15:862-70.

45. Jones TB, Basso DM, Sodhi A, Pan JZ, Hart RP, MacCallum RC, et al. Pathological CNS autoimmune disease triggered by traumatic spinal cord injury: implications for autoimmune vaccine therapy. J Neurosci. 2002;22:2690-700.

46. Kil K, Zang YC, Yang D, Markowski J, Fuoco GS, Vendetti GC, et al. T cell responses to myelin basic protein in patients with spinal cord injury and multiple sclerosis. J Neuroimmunol. 1999;98:201-7.

47. Popovich PG, Stokes BT, Whitacre CC. Concept of autoimmunity following spinal cord injury: possible roles for T lymphocytes in the traumatized central nervous system. J Neurosci Res. 1996;45:349-63.

48. Chamberlain G, Fox J, Ashton B, Middleton J. Concise review: mesenchymal stem cells: their phenotype, differentiation capacity, immunological features, and potential for homing. Stem Cells. 2007;25:2739-49.

49. Rice CM, Scolding NJ. Adult human mesenchymal cells proliferate and migrate in response to chemokines expressed in demyelination. Cell Adh Migr. 2010;4:235-40

50. Richter-Landsberg C, Heinrich M. OLN-93: a new permanent oligodendroglia cell line derived from primary rat brain glial cultures. J Neurosci Res. 1996;45:161-73.

51. Jana A, Pahan K. Oxidative stress kills human primary oligodendrocytes via neutral sphingomyelinase: implications for multiple sclerosis. J Neuroimmune Pharmacol. 2007:2:184-93.

52. Vondran MW, Clinton-Luke P, Honeywell JZ, Dreyfus CF. BDNF+/- mice exhibit deficits in oligodendrocyte lineage cells of the basal forebrain. Glia. 2010;58:848-56.

53. Akerud P, Canals JM, Snyder EY, Arenas E. Neuroprotection through delivery of glial cell line-derived neurotrophic factor by neural stem cells in a mouse model of Parkinson's disease. J Neurosci. 2001;21:8108-18.

54. Kim HM, Hwang DH, Lee JE, Kim SU, Kim BG. Ex vivo VEGF delivery by neural stem cells enhances proliferation of glial progenitors, angiogenesis, and tissue sparing after spinal cord injury. Plos One. 2009;4:e4987.

55. Lu Z, Hu X, Zhu C, Wang D, Zheng X, Liu Q. Overexpression of CNTF in mesenchymal stem cells reduces demyelination and induces clinical recovery in experimental autoimmune encephalomyelitis mice. J Neuroimmunol. 2009;206:58-69.

56. Said EA, Dupuy FP, Trautmann L, Zhang Y, Shi Y, El-Far M, et al. Programmed death-1-induced interleukin-10 production by monocytes impairs CD4+ T cell activation during HIV infection. Nat Med. 2010;16:452-9.

57. Jacobs SA, Pinxteren J, Roobrouck VD, Luyckx A, van't Hof W, Deans R, et al. Human multipotent adult progenitor cells are nonimmunogenic and exert 
potent immunomodulatory effects on alloreactive T-cell responses. Cell Transplant. 2013;22:1915-28.

58. Kovacsovics-Bankowski M, Streeter PR, Mauch KA, Frey MR, Raber A, van't Hof W, et al. Clinical scale expanded adult pluripotent stem cells prevent graft-versus-host disease. Cell Immunol. 2009;255:55-60.

59. Carrade Holt DD, Wood JA, Granick JL, Walker NJ, Clark KC, Borjesson DL. Equine mesenchymal stem cells inhibit T cell proliferation through different mechanisms depending on tissue source. Stem Cells Dev. 2014;23:1258-65.

60. Meisel R, Zibert A, Laryea M, Gobel U, Daubener W, Dilloo D. Human bone marrow stromal cells inhibit allogeneic T-cell responses by indoleamine 2,3-dioxygenase-mediated tryptophan degradation. Blood. 2004;103:4619-21.

61. Luyckx A, De Somer L, Rutgeerts O, Waer M, Verfaillie CM, Van Gool S, et al. Mouse MAPC-mediated immunomodulation: cell-line dependent variation. Exp Hematol. 2010;38:1-2.

62. Ren G, Su J, Zhang L, Zhao X, Ling W, L'Huillie A, et al. Species variation in the mechanisms of mesenchymal stem cell-mediated immunosuppression. Stem Cells. 2009;27:1954-62.

63. Schnabel LV, Abratte CM, Schimenti JC, Felippe MJ, Cassano JM, Southard $T L$, et al. Induced pluripotent stem cells have similar immunogenic and more potent immunomodulatory properties compared with bone marrow-derived stromal cells in vitro. Regen Med. 2014;9:621-35.

64. Balashov KE, Rottman JB, Weiner HL, Hancock WW. CCR5(+) and CXCR3(+) T cells are increased in multiple sclerosis and their ligands MIP-1alpha and IP-10 are expressed in demyelinating brain lesions. Proc Natl Acad Sci U S A. 1999;96:6873-8.

65. Broux B, Pannemans K, Zhang X, Markovic-Plese S, Broekmans T, Eijnde BO, et al. CX(3)CR1 drives cytotoxic CD4(+)CD28(-) T cells into the brain of multiple sclerosis patients. J Autoimmun. 2012;38:10-9.

66. Simpson J, Rezaie P, Newcombe J, Cuzner ML, Male D, Woodroofe MN Expression of the beta-chemokine receptors CCR2, CCR3 and CCR5 in multiple sclerosis central nervous system tissue. J Neuroimmunol. 2000;108:192-200.

67. Sorensen TL, Trebst C, Kivisakk P, Klaege KL, Majmudar A, Ravid R, et al. Multiple sclerosis: a study of CXCL10 and CXCR3 co-localization in the inflamed central nervous system. J Neuroimmunol. 2002;127:59-68.

68. Chuntharapai A, Lee J, Hebert CA, Kim KJ. Monoclonal antibodies detect different distribution patterns of IL-8 receptor $A$ and IL-8 receptor $B$ on human peripheral blood leukocytes. J Immunol. 1994;153:5682-8.

69. Carrero R, Cerrada I, Lledo E, Dopazo J, Garcia-Garcia F, Rubio MP, et al. IL1 beta induces mesenchymal stem cells migration and leucocyte chemotaxis through NF-kappaB. Stem Cell Rev. 2012;8:905-16.

70. Cohen ME, Fainstein N, Lavon I, Ben-Hur T. Signaling through three chemokine receptors triggers the migration of transplanted neural precursor cells in a model of multiple sclerosis. Stem Cell Res. 2014;13:227-39.

71. Jackson JS, Golding JP, Chapon C, Jones WA, Bhakoo KK. Homing of stem cells to sites of inflammatory brain injury after intracerebral and intravenous administration: a longitudinal imaging study. Stem Cell Res Ther. 2010;1:17.

72. Ries C, Egea V, Karow M, Kolb H, Jochum M, Neth P. MMP-2, MT1-MMP, and TIMP-2 are essential for the invasive capacity of human mesenchymal stem cells: differential regulation by inflammatory cytokines. Blood. 2007;109:4055-63.

73. Aranguren XL, Pelacho B, Penuelas I, Abizanda G, Uriz M, Ecay M, et al. MAPC transplantation confers a more durable benefit than $\mathrm{AC} 133+$ cell transplantation in severe hind limb ischemia. Cell Transplant. 2011;20:259-69.

74. Busch SA, Hamilton JA, Horn KP, Cuascut FX, Cutrone R, Lehman N, et al Multipotent adult progenitor cells prevent macrophage-mediated axonal dieback and promote regrowth after spinal cord injury. J Neurosci. 2011;31:944-53.

75. Pelacho B, Nakamura Y, Zhang J, Ross J, Heremans Y, Nelson-Holte M, et al. Multipotent adult progenitor cell transplantation increases vascularity and improves left ventricular function after myocardial infarction. J Tissue Eng Regen Med. 2007;1:51-9.

76. Zeis T, Graumann U, Reynolds R, Schaeren-Wiemers N. Normal-appearing white matter in multiple sclerosis is in a subtle balance between inflammation and neuroprotection. Brain. 2008;131:288-303.

77. Freedman MS, Bar-Or A, Atkins HL, Karussis D, Frassoni F, Lazarus H, et al. The therapeutic potential of mesenchymal stem cell transplantation as a treatment for multiple sclerosis: consensus report of the International MSCT Study Group. Mult Scler. 2010;16:503-10.

\section{Submit your next manuscript to BioMed Central and take full advantage of:}

- Convenient online submission

- Thorough peer review

- No space constraints or color figure charges

- Immediate publication on acceptance

- Inclusion in PubMed, CAS, Scopus and Google Scholar

- Research which is freely available for redistribution

Submit your manuscript at www.biomedcentral.com/submit 